\title{
Advances in signaling in vertebrate regeneration as a prelude to regenerative medicine
}

\author{
Cristi L. Stoick-Cooper, ${ }^{1,2}$ Randall T. Moon, ${ }^{1,4}$ and Gilbert Weidinger ${ }^{3}$ \\ ${ }^{1}$ Department of Pharmacology, Howard Hughes Medical Institute, and Institute for Stem Cell and Regenerative Medicine, \\ University of Washington School of Medicine, Seattle, Washington 98195, USA; ${ }^{2}$ University of Washington Graduate \\ Program in Neurobiology and Behavior, University of Washington School of Medicine, Seattle, Washington 98195, USA; \\ ${ }^{3}$ Biotechnological Center and Center for Regenerative Therapies, University of Dresden, Dresden 01377, Germany
}

While all animals have evolved strategies to respond to injury and disease, their ability to functionally recover from loss of or damage to organs or appendages varies widely damage to skeletal muscle, but, unlike amphibians and fish, they fail to regenerate heart, lens, retina, or appendages. The relatively young field of regenerative medicine strives to develop therapies aimed at improving regenerative processes in humans and is predicated on $>40$ years of success with bone marrow transplants. Further progress will be accelerated by implementing knowledge about the molecular mechanisms that regulate regenerative processes in model organisms that naturally possess the ability to regenerate organs and/or appendages. In this review we summarize the current knowledge about the signaling pathways that regulate regeneration of amphibian and fish appendages, fish heart, and mammalian liver and skeletal muscle. While the cellular mechanisms and the cell types involved in regeneration of these systems vary widely, it is evident that shared signals are involved in tissue regeneration. Signals provided by the immune system appear to act as triggers of many regenerative processes. Subsequently, pathways that are best known for their importance in regulating embryonic development, in particular fibroblast growth factor (FGF) and Wnt/ $\beta$-catenin signaling (as well as others), are required for progenitor cell formation or activation and for cell proliferation and specification leading to tissue regrowth. Experimental activation of these pathways or interference with signals that inhibit regenerative processes can augment or even trigger regeneration in certain contexts.

\section{What is regeneration?}

All organisms have evolved strategies to maintain their function and form throughout adult life. Many differentiated cell types are short-lived and need to be continu-

[Keywords: Wnt; FGF; blastema; zebrafish; Xenopus; limb]

${ }^{4}$ Corresponding author.

E-MAIL rtmoon@u.washington.edu; FAX (206) 543-0858.

Article is online at http://www.genesdev.org/cgi/doi/10.1101/gad.1540507. ously replaced. Prominent examples of such homeostatic replacement are found in the vertebrate blood lineage, gut epithelium, and skin. Furthermore, many organisms freely part with substantial parts of their body and replace them, in many cases repeatedly throughout life. Examples include the shedding cycles of the crustacean exoskeleton and snake skin, the annual replacement of bird feathers, the dramatic loss and regrowth of deer antlers, and the renewal of the endometrium after a menstrual period in mammals.

In addition to these physiological phenomena of reconstitution, all animals have means of dealing with damage due to injury or disease. Healing of epidermal wounds is an efficient process of repair in most organisms, but the ability to recover from damage to other organs or structures varies widely in different organisms. Some invertebrates, such as planarians or annelid worms, can regrow all missing body parts when cut into small pieces, while some vertebrates, such as amphibia, can replace lost limbs, tails, lens, retina, and several internal organs and repair skeletal muscle, peripheral nervous system and CNS. Fish can also regrow amputated hearts. Mammals (including humans) can repair damage to skeletal muscle and peripheral nervous system and can recover from damage to the liver, but lack the ability of amphibia and fish to regrow appendages, heart, lens, retina, and CNS.

The term "regeneration" has been used to describe all the phenomena mentioned above, including the homeostatic reconstitution of short-lived cell types (e.g., blood), the whole body re-establishment of organisms like planaria, and all phenomena in between. This clearly covers phenomena of very different kinds; thus, a clear definition of what "regeneration" is and how it differs from "repair" or "reconstitution" is not in sight. In our view, it is useful to look at repair in animals as a continual spectrum of phenomena that share many mechanistic principles. Therefore, for the purpose of this review, we use a quite inclusive definition of regeneration that includes all of the above-mentioned processes and simply defines regeneration as a processes that allows an 
organism to regain the function of an organ or structure damaged by injury or disease. We focus on regeneration in vertebrates, where we distinguish three types of regeneration: (1) "Epimorphic": regeneration via formation of a blastema, a population of progenitor cells that arises through epithelial mesenchymal interactions and contains intrinsic morphogenetic information that is required to repattern the regenerating structure (e.g., limb, tail, and fin regeneration). (2) "Compensatory growth": here it is not the damaged part of an organ that is restored, but uninjured parts of the organ compensate for the loss by growth (e.g., after removal of two lobes of the liver, the third lobe grows until the original mass of the liver is restored). (3) "Tissue regeneration": repair of local, limited damage to an organ predominantly via restoration of only one cell type (e.g., skeletal muscle).

These regenerative processes include phenomena of very different complexities: compensatory growth of the liver after partial hepatectomy, where existing hepatocytes replicate without activation of progenitor cells, and repair of local damage to muscle by production of new muscle fibers are both certainly much less complicated processes than regrowth of a limb containing many different cell types that are organized into tissues and patterned along the proximal-distal, dorsal-ventral, and anterior-posterior axes. Nevertheless, all regenerative processes need to be tightly regulated and involve communication between different cell types. In this review, we give an overview of the current knowledge about signaling pathways regulating vertebrate regeneration, concentrating on selected systems that are fairly well understood or of high clinical relevance. Tables 1 and 2 summarize key cellular and molecular events in regeneration of these systems.

\section{Limb regeneration}

The ability of vertebrates to regenerate limbs varies greatly. The true champions of limb regeneration are urodele amphibians (newts and salamanders), which possess the ability to regenerate amputated limbs anytime during their life (for review, see Roy and Levesque 2006). Anuran amphibians (frogs) can regenerate limbs during larval stages, but progressively lose this capability during further development (Dent 1962; Muneoka et al. 1986b). Amputated or severed limbs in adult mammals and chickens do not regenerate at all; however, digit tips of mature mammalian limbs do possess regenerative capabilities (Douglas 1972; Illingworth 1974; Borgens 1982). Much has been learned by studying limb regeneration in each organism, from both the standpoint of what is required for a regenerative limb to regenerate as well as how to induce a nonregenerative limb to do so. Here we review the molecular and cellular events that occur during each step of limb regeneration-the culmination of what we have learned from each organism.

\section{Wound healing}

The first step in limb regeneration is healing of the wound, which occurs differently in nonregenerative and regenerating limbs. Following an inflammatory response, a large wound in mammals takes days to close and results in the accumulation of collagen bundles that form scar tissue (for review, see Martin 1997; Han et al. 2005). In contrast, after amputation of the urodele or larval anuran limb, the surface of the wound is covered rapidly (within a matter of hours) with epidermal cells that migrate from the edge of the amputation surface, forming the "wound epidermis" (WE) (for review, see Call and Tsonis 2005). It is not known what immediate signals induce cells to migrate to cover the wound, but it is known that the formation of the WE is required for regeneration to occur (Thornton 1957). Matrix metalloproteinases (MMPs) are up-regulated very early after amputation and are required for regeneration, and it is postulated that they play a role in matrix degradation, contributing to formation of the WE (Call and Tsonis 2005; Vinarsky et al. 2005). The WE becomes a specialized structure (that some call the apical epithelial cap [AEC]), which is distinct morphologically and in gene expression from the normal epithelium (for review, see Call and Tsonis 2005; Han et al. 2005). This structure is thought to be similar to the apical ectodermal ridge (AER) that is present in the developing limb bud, which directs and patterns limb outgrowth in amniotes (Summerbell 1974; Saunders et al. 1976; Saunders 1998), but there is some debate about how similar these structures actually are. This is due, in part, to the fact that after amputation of a regenerating limb with a WE (or AEC), the AEC (and limb) regenerates, but after amputation of a developing limb with an AER (like the chick limb bud), the AER does not regenerate, and neither does the developing limb (Tschumi 1957; Hayamizu et al. 1994). Recent evidence shows that $\mathrm{Wnt} / \beta$-catenin signaling is required for structural maturation of the WE in axolotls and frogs, but not for the earlier phase of epidermal migration after wounding (Kawakami et al. 2006).

\section{Blastema formation}

Signals from the WE are thought to induce formation of the "regeneration blastema," which is comprised of progenitor cells that accumulate at the amputation plane, proliferate, and differentiate to direct regeneration at the distal tip of the regenerating limb (for review, see Wallace 1981; Tsonis 1996). The blastema is thought to be formed by differentiated cells that dedifferentiate upon amputation of the limb and/or by activation of resident stem cells.

It has been shown that differentiated cells of many tissues in the urodele limb stump dedifferentiate to give rise to the blastema (Muneoka et al. 1986a; Echeverri et al. 2001). In vitro and in vivo evidence demonstrates that muscle tissue dedifferentiates from multinucleated myotubes (in culture) and myofibers (in vivo) to form mononucleated cells that proliferate and contribute to the blastema (Namenwirth 1974; Lo et al. 1993; Kumar et al. 2000; Echeverri et al. 2001; Brockes and Kumar 2002). Tanaka et al. (1999) have shown that the bloodclotting proteinase thrombin may act as an extracellular 
Stoick-Cooper et al.

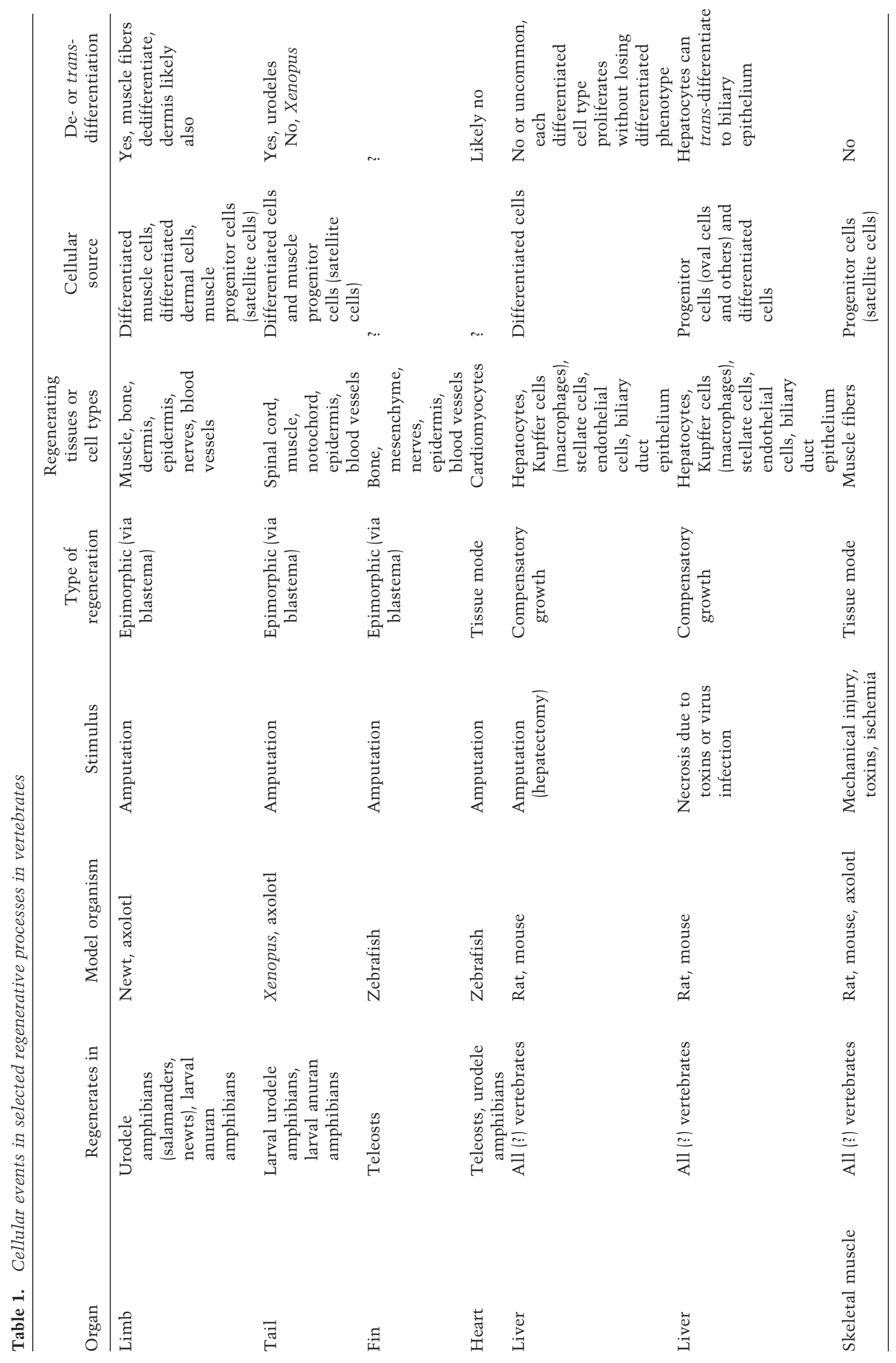


Table 2. Signaling events in selected regenerative processes in vertebrates

\begin{tabular}{|c|c|c|c|c|c|c|}
\hline Organ & Trigger & $\begin{array}{l}\text { Activating } \\
\text { cellular source } \\
\text { (blastema } \\
\text { formation in } \\
\text { epimorphic } \\
\text { regeneration) }\end{array}$ & $\begin{array}{l}\text { Controlling } \\
\text { proliferation }\end{array}$ & $\begin{array}{l}\text { Controlling } \\
\text { cell fate }\end{array}$ & $\begin{array}{l}\text { Controlling } \\
\text { morphogenesis }\end{array}$ & Inhibiting \\
\hline Limb & Thrombin (?) & $\begin{array}{l}\text { Wnt } / \beta \text {-cat } \\
\text { FGF } \\
\text { BMP }\end{array}$ & $\begin{array}{l}\text { Thrombin } \\
\text { Rb } \\
\text { phosphorylation } \\
\text { BMP }\end{array}$ & ? & $\begin{array}{l}\text { RA } \\
\text { Shh (A/P axis) }\end{array}$ & $?$ \\
\hline Tail & $?$ & $\begin{array}{l}\text { BMP } \\
\text { Notch }\end{array}$ & $\begin{array}{l}\text { BMP } \\
\text { Shh }\end{array}$ & $\begin{array}{l}\text { BMP } \\
\text { Shh }\end{array}$ & Shh (D/V axis) & $?$ \\
\hline Fin & $?$ & $\begin{array}{l}\text { Wnt } / \beta \text {-cat } \\
\text { FGF }\end{array}$ & $\begin{array}{l}\text { Wnt } / \beta \text {-cat } \\
\text { FGF } \\
\text { BMP }\end{array}$ & $\begin{array}{l}\text { Shh (bone) } \\
\text { Notch }\end{array}$ & RA & $\begin{array}{l}\text { Wnt } / \beta \text {-cat } \\
\text { independent } \\
\text { SDF1 (?) }\end{array}$ \\
\hline Heart & $?$ & $?$ & $?$ & $\begin{array}{l}\text { FGF } \\
\text { (vasculogenesis) }\end{array}$ & $?$ & $?$ \\
\hline $\begin{array}{l}\text { Liver- } \\
\text { hepatectomy }\end{array}$ & $\begin{array}{l}\text { Innate immune } \\
\text { system } \\
\text { (microbial } \\
\text { endotoxins) } \\
\text { Complement } \\
\text { system (C3a, } \\
\text { C5a) } \\
\text { Serotonin released } \\
\text { from platelets (?) }\end{array}$ & $\begin{array}{l}\text { TNF or ligands } \\
\text { of same } \\
\text { receptor }\end{array}$ & $\begin{array}{l}\text { HGF } \\
\text { EGF-family } \\
\text { FGF (?) } \\
\text { Wnt/ß-cat (?) }\end{array}$ & n. a. & $?$ & $\begin{array}{l}\text { TGF } \beta \text { and } \\
\text { similar, like } \\
\text { activin }\end{array}$ \\
\hline $\begin{array}{l}\text { Liver-toxic } \\
\text { injury }\end{array}$ & $\begin{array}{l}\text { Likely similar to he } \\
\text { TNF-related ligand }\end{array}$ & $\begin{array}{l}\text { atectomy-induces } \\
\text { WEAK specificall }\end{array}$ & $\begin{array}{l}\text { regeneration } \\
\text { activates oval cells }\end{array}$ & & & \\
\hline Skeletal muscle & $\begin{array}{l}\text { Chemoattractants } \\
\text { for immune } \\
\text { system cells }\end{array}$ & $\begin{array}{l}\text { TWEAK } \\
\text { TNF } \alpha(?)\end{array}$ & $\begin{array}{l}\text { IGF } \\
\text { FGF6(?) }\end{array}$ & $\begin{array}{l}\text { Notch } \\
\text { FGF6(?) }\end{array}$ & $?$ & Myostatin \\
\hline
\end{tabular}

signal that induces this process, as it can indirectly induce S-phase re-entry in cultured newt myotubes. It is also known that, intracellularly, phosphorylation of the retinoblastoma $(\mathrm{Rb})$ protein and expression of the homeobox protein Msx1, a transcriptional repressor that is expressed in many regenerating systems, is required for myotube cell cycle re-entry in vitro (Tanaka et al. 1997; Kumar et al. 2004).

Many studies describe the role of the dermis in contributing to the formation of the blastema; it is distinct in this way from the epidermis, which is known to only contribute to formation of the WE (Riddiford 1960; Hay and Fischman 1961; Endo et al. 2004). Cells of the dermis can give rise to multiple cell types in the regenerating limb, including cartilage and connective tissue (Dunis and Namenwirth 1977); however, the molecular signals that govern this process are not understood. Cartilage cells also have been shown to dedifferentiate to participiate in the blastema formation during limb regeneration (Steen 1968; Namenwirth 1974; Muneoka et al. 1986a), but extensive studies have not been done to uncover the molecular signals involved in this process either. It is known, however, that Wnt7a can induce dedifferentiation of mammalian chondrocytes in vitro, by stimulating $\beta$-catenin-mediated transcription (Hwang et al. 2004).

In urodeles, it has been recently shown that pax7-expressing muscle satellite cells, which are well-described muscle progenitor cells in mammalian muscle formation and regeneration (see below), become mitotically active after limb amputation (Morrison et al. 2006). Moreover, pax7-expressing cells are found in the blastema, suggesting that these cells may participate in blastema formation. This is a surprising and somewhat controversial finding, however, because most research in the field points to dedifferentiation as playing the major role in forming the urodele blastema.

During blastema formation, the WE in both urodeles and larval anurans begins to express fibroblast growth factor 8 (fgf8) (Christen and Slack 1997; Han et al. 2001; 
Christensen et al. 2002). fgf8 and $f g f 10$ expression correlates with regenerative capacity in Xenopus; amputation at a later, nonregenerative stage of development fails to result in the formation of a blastema or expression of either of these $f g f$ genes (Yokoyama et al. 2000). By inhibiting FGF signaling with pharmacological inhibitors, D'Jamoos et al. (1998) demonstrated a requirement for this signaling pathway during Xenopus limb regeneration. Importantly, treatment of a nonregenerative-stage Xenopus limb stump after amputation with FGF8soaked beads results in partial regeneration, and treatment with FGF10 stimulates expression of several genes that are expressed in regenerating limbs, including $s h$, $m s \times 1$, and $f g f 10$, and results in significant regeneration (Yokoyama et al. 2001). Similar studies in the chick, where amputation of the limb bud always results in regeneration failure (no matter what stage), show that treatment of the amputation surface with FGF2 or FGF4 induces a regenerative response (Taylor et al. 1994; Kostakopoulou et al. 1996).

Using a stable transgenic line of Xenopus in which expression of the soluble bone morphogenetic protein (BMP) inhibitor noggin is under the control of a heatshock-inducible promoter, Beck et al. (2006) showed that BMP signaling is required for blastema formation, $m s \times 1$ and $f g f 8$ expression, and proliferation of cells in the epidermis as well as the blastema. Recent loss-of-function studies point to a similar role for Wnt/ $\beta$-catenin signaling during limb regeneration (Kawakami et al. 2006; Yokoyama et al. 2007). Inhibition of Wnt/ $\beta$-catenin signaling early during the process of limb regeneration completely inhibits regeneration in both the axolotl and Xenopus (Kawakami et al. 2006; Yokoyama et al. 2007), while inhibition later, after the blastema has formed, causes a partial regenerative response, where some, but not all digits of the limb regenerate (Yokoyama et al. 2007). Furthermore, reduced Wnt $/ \beta$-catenin signaling abolishes $f g f 8$, but not $f g f 10$, expression, suggesting that Wnt $/ \beta$-catenin signaling acts upstream of $f g f 8$ and downstream from, or in parallel with, $f g f 10$ (Yokoyama et al. 2007). Wnt3a is a candidate Wnt ligand that may mediate these effects, since it is expressed in the same region as fgf8 in the regenerating blastema (Yokoyama et al. 2007). Regeneration of later-stage Xenopus limbs, at a stage when the regenerative response is reduced, and of the nonregenerative developing chick limb is rescued after treatment with a $\beta$-catenin-expressing virus, demonstrating that Wnt $/ \beta$-catenin signaling is sufficient to induce regeneration in a nonregenerative limb (Kawakami et al. 2006).

\section{Nerve-derived signals}

It is well known that limb regeneration requires innervation (for review, see Wallace 1981). It has been suggested that axons secrete what have been called "neurotrophic factors" into the amputated limb and that these factors up-regulate genes important for the regenerative process. FGF2 may be one such factor (Mullen et al. 1996). It is detected at the protein level in the WE and in nerves, and its expression decreases dramatically after denervation. Furthermore, FGF2-soaked beads can rescue regeneration in denervated regenerates (Mullen et al. 1996). It has been recently shown that innervation is required for maintenance of expression of genes in the early blastema of the froglet, including tbx5 and prx 1 , and for initiation of expression of $m s \times 1, f g f 8$, and $f g f 10$ in the late blastema (Suzuki et al. 2005). fgf8 and fgf10 expression levels are also reduced in the denervated blastema of the axolotl (Christensen et al. 2001), suggesting that the requirement of neuronal input for FGF expression is a conserved feature among species.

\section{Signals regulating morphogenesis}

The ability of cells to determine their position in three dimensions is crucial to the establishment of proper patterning in a developing or regenerating organ. Classical experiments show that retinoic acid (RA) instructs positional identity in regenerating anuran tadpole or urodele limbs (Niazi and Saxena 1978; Maden 1982). Normally, amphibia regenerate only the missing part of a limb after amputation. In contrast, in an excess of RA, limbs amputated at the wrist level will not only regenerate a hand or foot, but an additional entire limb, resulting in a limb that is duplicated along the proximodistal axis. This has been shown to be dose-dependent in that decreasing amounts of RA results in distalization of the duplicated regenerate (Thoms and Stocum 1984). In addition to the role RA plays in patterning of the proximodistal axis, it has also been shown to affect dorsoventral patterning of the regenerating axolotl limb as well (Ludolph et al. 1990). Endogenously, it is thought that the role of RA is to specify proximal identities by acting through the GPIanchored cell surface molecule prod1 (da Silva et al. 2002) and through meis1 and meis2, two homeobox genes that are RA targets during limb development (Mercader et al. 2000) as well as in limb regeneration (Mercader et al. 2005). Shh is also expressed after limb amputation in urodeles (Imokawa and Yoshizato 1997; Torok et al. 1999) and in regenerating limb buds of anurans (Endo et al. 1997), and functional evidence suggests that Shh is important for imparting anterior-posterior axis information to the regenerating limb (Roy et al. 2000; Roy and Gardiner 2002), much like it does during limb development in other species (Riddle et al. 1993).

\section{Mammalian digit tip regeneration}

Only the ends of digits regenerate in mammals. Using an in vitro digit tip regeneration model, Han et al. (2003) showed that Msx1 mutant mice display a regeneration defect. This can be rescued with BMP4, and wild-type digit tip regeneration can be inhibited with Noggin, implicating BMP signaling as being required for this process, likely downstream from Msx1 (Han et al. 2003). An encouraging discovery in humans, made $>30$ years ago, is that fingertip amputations result in regeneration (Doug- 
las 1972; Illingworth 1974), much like mouse digit tips. Whether a fingertip can regenerate or not is based on the level where it was amputated; successful regeneration is reported following amputation through the proximal region of the distal phalanx (Illingworth 1974). Functional analysis of this phenomenon has been impossible in humans until recently. Allan et al. (2006) describe an in vitro human fetal digit tip regeneration assay, in which human fetal digits regrow tissue in response to amputation and up-regulate MSX1 expression $4 \mathrm{~d}$ post-amputation (dpa). This exciting technical development provides researchers with a new way to bring what we have learned about limb regeneration from other organisms to ask therapeutically relevant questions in humans.

\section{Summary}

Key events in limb regeneration are the establishment of a specialized WE and the subsequent formation of the progenitor cell population of the blastema. In urodeles, dedifferentiation of differentiated cells contributes to blastema formation. The cellular events that occur during limb regeneration are summarized in Table 1. While little is known about the signals regulating WE formation, it is evident that many of the pathways that regulate embryonic limb formation, in particular FGF and Wnt/ $\beta$-catenin signaling, are also essential for blastema formation and limb regeneration. Likewise, patterning and morphogenesis of the regenerating limb are established by signals that are essential for these processes during development, namely, Shh and RA. The signals that regulate limb regeneration are summarized in Figure 1 and Table 2.

\section{Tail regeneration}

Urodele amphibians and anuran tadpoles can also regenerate their tails, including spinal cord, notochord, and muscle (Bosco 1979; Brockes 1997). This occurs through the same steps as limb regeneration: wound healing, blastema formation, and outgrowth. The general cellular processes appear to be quite similar at each step of tail regeneration when compared with limb regeneration. Interestingly, though, with regard to tail regeneration, there appear to be differences between species. Specifically, it is clear that muscle regeneration differs between urodeles and anurans. In vivo imaging demonstrates that muscle fiber dedifferentiation is a major contributor to the regenerating tail blastema in the larval axolotl (Echeverri et al. 2001). However, the case is completely different in Xenopus tail regeneration, where myofibers do not dedifferentiae (Ryffel et al. 2003; Gargioli and Slack 2004). Rather, pax7-expressing satellite cells are the muscle cell precursors in Xenopus tail regeneration (Chen et al. 2006). Another cellular aspect of Xenopus tail regeneration, recently discovered by Tseng et al. (2007), is that apoptosis is required during the first $24 \mathrm{~h}$ post-amputation (hpa). When Caspase-3 activity is inhibited, regeneration is abolished. Tseng et al. (2007) interpret these results to mean that there may exist endogenous inhibitory cells that must be destroyed by programmed cell death for regeneration to occur.

It was formerly thought that the tail of the Xenopus tadpole could regenerate at all stages up until metamorphosis, but it has recently been shown that this is not the case (Beck et al. 2003). In particular, at stage 46/47, there is a "refractory period" during which most tadpoles heal over the wound and fail to regenerate. If tadpoles are allowed to grow to a later stage (around stage 49) and are then amputated, the tail does regenerate. The causes of the refractory period are not understood, but it provides a model with which to study molecules that might promote regeneration. Additionally, in the same system, one can test inhibitors of regeneration at later stages.

By using constitutively active or dominant-negative gene products, induced under the control of a heat-shock promoter, the roles of BMP and Notch signaling in tail regeneration were uncovered (Beck et al. 2003). When BMP signaling is inhibited before amputation of a nor-
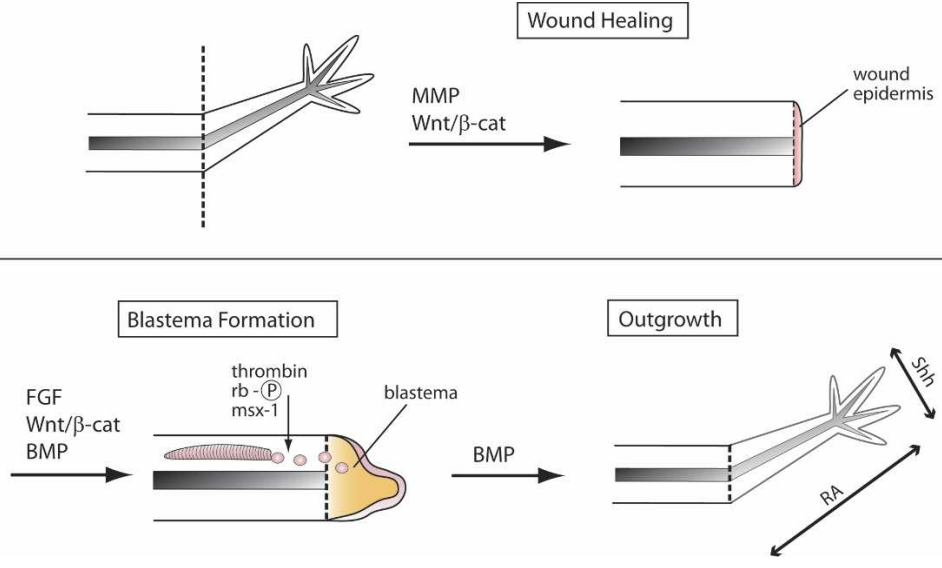

Figure 1. Major signaling events regulating vertebrate limb regeneration. The cartoon combines signals that were found to be required in vivo or were implicated to be involved by in vitro data. Regeneration occurs in three steps. (1) Wound healing and formation of a specialized WE require Wnt $/ \beta$-catenin signaling and the action of MMPs. (2) Wnt $/ \beta$-catenin signaling, together with FGF and BMP signals, is also required for blastema formation. In urodele amphibia, dedifferentiation of muscle fibers contributes to establishment of the blastema. The blood-clotting proteinase thrombin is implicated in re-entry of muscle cells into the cell cycle, as is phosphorylation and inactivation of the Rb protein. Forced expression of the homeobox transcriptional repressor msx 1 is sufficient to cause dedifferentia-

tion of muscle fibers in culture. (3) BMP signaling is required for blastema proliferation during regenerative outgrowth, while Shh is essential for patterning of the limb along the anteroposterior axis. RA regulates patterning along the proximal-distal axis and thus controls positional memory. 
mally regenerative tail by induction of Noggin, an extracellular inhibitor of BMP signaling (Smith and Harland $1992)$, or tBR, a truncated BMP receptor that behaves as a dominant negative (Suzuki et al. 1994), regeneration is halted (Beck et al. 2003). By initiating heat shocks of hsp70-noggin transgenic tadpoles at different times, Beck et al. (2006) discovered that the requirement for BMP signaling in tail regeneration is relatively late, 24$48 \mathrm{hpa}$. It is specifically required for the induction of msx1 expression and cellular proliferation in the notochord and spinal cord. Interestingly, in transgenic frogs expressing Alk3, a constitutively active form of the type I BMP receptor that stimulates the BMP pathway, regeneration of the tail during the "refractory period" is restored with all components of the tail-including muscle, spinal cord, notochord, and fin-regrowing normally (Beck et al. 2003). Msx1, which is directly activated by BMP signaling (Suzuki et al. 1997), is re-expressed in Alk3 transgenics that display "rescued" regeneration during the refractory period. Furthermore, activating msx 1 in transgenic frogs amputated during the refractory period stimulates normal regeneration, suggesting that $m s \times 1$ can substitute for BMP signaling in tail regeneration and is likely an important regulator of the mechanism by which BMP signaling stimulates regeneration (Beck et al. 2003). These data suggest that BMP signaling is not only required for regeneration of a regenerative stage tail, but is also sufficient to promote regeneration of the tail during the refractory period. Furthermore, since BMP signaling regulates proliferation of only notochord and spinal cord cells, but can rescue regeneration of the entire tail when overexpressed, Beck et al. (2006) hypothesize that the driving force behind tail tissue regeneration comes from these midline structures.

Notch signaling is also required for normal tail regeneration as inhibition of Notch signaling with the drug MG132 completely abolishes tail regeneration (Beck et al. 2003). Overexpression of the constitutively active Notch intracellular domain (NICD) during the refractory period stimulates the regeneration of a tail that contains notochord and spinal cord, but little to no muscle. Furthermore, Notch signaling appears to act downstream from BMP signaling because MG132 inhibits regeneration induced during the refractory period by Alk3. In addition, the NICD can induce regeneration during the refractory period even when tBR is also expressed. It is important to note that the effects of the NICD/tBR were comparable with the effects of the NICD treatment alone in that no muscle regenerates in the tail (Beck et al. 2003). This implies that the BMP pathway has a separate effect on muscle regeneration that is independent of Notch signaling.

Evidence for the role of Shh signaling comes from studies using the pharmacological inhibitor cyclopamine, which revealed that hedgehog signaling is not only required for dorsoventral patterning of the regenerating spinal cord, but also for regeneration of surrounding mesodermal tissues (Schnapp et al. 2005). Proliferation of blastemal cells was reduced, resulting in an overall inhibition of tail regeneration. Furthermore, expression of sox9, a cartilage cell marker, was lost. Interestingly, these roles for Shh signaling during tail regeneration are distinct from the role of Shh in limb regeneration, where it is involved in anteroposterior patterning (Roy and Gardiner 2002; Schnapp et al. 2005). These data point out that, while some signaling pathways play similar roles in regeneration of different organs and/or appendages, it is also possible that the same signaling pathway can play completely different roles in different regenerating organs.

\section{Summary}

Tail regeneration occurs in similar steps as limb regeneration and involves formation of a blastema. In this paradigm, however, differences between species in the cellular mechanisms involved are evident: Dedifferentiation occurs in urodeles, but not anuran amphibians. The cellular events that occur during tail regeneration are summarized in Table 1. Most of our knowledge of the signals regulating the process comes from frogs, where BMP and Notch signaling have been identified as major players. Intriguingly, experimental activation of BMP signaling is sufficient to induce complete tail regeneration in frog larvae. The molecular signals that are involved in tail regeneration are summarized in Table 2.

\section{Fin regeneration}

Urodeles are the classic model for study of epimorphic regeneration, long heralded as such because of their truly amazing regenerative abilities. Until recently, however, molecular studies in these organisms have been hindered by the lack of well-developed molecular and genetic techniques. While recent advances in transgenic technology open new avenues for molecular analysis of regeneration in axolotl, zebrafish have been emerging as a model for regeneration studies as well. Zebrafish can regenerate many structures including the heart, retina, spinal cord, and fin and, importantly, are also highly amenable to standard molecular and genetic techniques (for review, see Akimenko et al. 2003; Poss et al. 2003). The caudal fin has become a popular model for studying the molecular mechanisms regulating regeneration due to its accessibility to amputation and its fairly simple structure, consisting of segmented bony fin rays. Each ray is comprised of concave, facing hemirays that surround connective tissue, as well as nerves and blood vessels. After amputation, zebrafish fins regenerate much like amphibian limbs, in that regeneration proceeds through three general steps: wound healing, blastema formation, and outgrowth. This occurs quickly, in $\sim 7-14$ $d$, with fins regenerating faster in warmer water (Johnson and Weston 1995).

\section{Wound healing}

Within the first 1-3 hpa, cells migrate to cover the wound by forming a thin epithelial layer. It is known 
that this process occurs without the proliferation of cells and does not require a blood supply (Santamaria et al. 1996; Poleo et al. 2001; Nechiporuk and Keating 2002; Santos-Ruiz et al. 2002; Bayliss et al. 2006); however, the molecular signals that initiate this process are unknown. Wound healing continues until 18-36 hpa, and during this time, it is known that several signaling molecules are up-regulated. fgf20 $a$ and wnt10a are both expressed within the first 6 hpa (Whitehead et al. 2005; StoickCooper et al. 2007). Importantly, loss-of-function studies for both fgf20a and Wnt/ $\beta$-catenin signaling (in fgf $20 a$ mutant fish and in transgenic fish overexpressing Dkk1, an inhibitor of Wnt/ $\beta$-catenin signaling [hsDkk1GFP], or wild-type fish infected with an adenovirus expressing Dkk1) show that, although cells migrate to cover the wound in both cases, an abnormal and incorrectly specified WE forms (Whitehead et al. 2005; Kawakami et al. 2006; Stoick-Cooper et al. 2007). Blood vessels heal during this time, and regenerative angiogenesis begins, the latter requiring vascular endothelial growth factor (VEGF) signaling (Huang et al. 2003; Bayliss et al. 2006). Interestingly, in the absence of angiogenesis, the fin can regenerate up to $\sim 1 \mathrm{~mm}$ before arresting (Bayliss et al. 2006).

\section{Blastema formation}

During the next phase of zebrafish fin regeneration, a blastema forms that is thought to be comprised of progenitor cells; however, it is not known where these progenitor cells come from. It is possible that either mature fin cells dedifferentiate or that quiescent stem cells are activated to form this pluripotent mass; however there is not direct evidence for either process. It appears likely that dedifferentiation plays the major contributing role to the formation of the blastema, however, since bromodeoxyuridine (BrdU) pulse-chase experiments have failed to reveal pre-existing slow-cycling stem cells that could contribute to the formation of the blastema (Nechiporuk and Keating 2002). In addition to their role in wound healing, it is also known that both Wnt/ $\beta$ catenin and FGF signaling pathways are required for blastema formation because inhibition of either pathway beginning after wound healing has taken place results in failure to express msx genes and absence of a blastema, causing complete regeneration failure (Poss et al. 2000; Stoick-Cooper et al. 2007). Our studies show that in hsDkk1GFP fish, expression of $f g f 20 a$ and the FGF target gene sprouty 4 are lost, suggesting that Wnt/ $\beta$-catenin signaling acts upstream of FGF signaling (Stoick-Cooper et al. 2007). However, the reciprocal experiment has not yet been performed, so it is possible that FGF signaling also induces $\mathrm{Wnt} / \beta$-catenin signaling in a positive feedback loop. Interestingly, there are also a couple of factors known to inhibit blastema formation when overexpressed, including Wnt5b and the chemokine, stromal cell-derived factor (SDF-1) (Dufourcq and Vriz 2006; Stoick-Cooper et al. 2007). These molecules may play a role in tightly regulating blastema formation and prolif- eration so that an inappropriately sized or overgrown blastema does not form.

\section{Regenerative outgrowth}

Between 2 and $4 \mathrm{dpa}$, the regenerating fin transitions into the outgrowth phase. The cell cycle speeds up, from a median G2 length of $>6 \mathrm{~h}$ during blastema formation to only $1 \mathrm{~h}$ during outgrowth (Nechiporuk and Keating 2002), and the fin begins to rapidly grow back. Blastemal cells differentiate into scleroblasts, which begin to secrete the matrix that will form the new bones, the lepidotrichia (Geraudie and Singer 1992; Santamaria et al. 1992; Becerra et al. 1996; Mari-Beffa et al. 1996). Both of the usual suspects, Wnt/ $\beta$-catenin signaling and FGF signaling, are still active and important for the outgrowth phase of fin regeneration; both pathways are required for expression of shh, which becomes an important player during this time (Laforest et al. 1998; Poss et al. 2000; Stoick-Cooper et al. 2007). Shh begins to be expressed in cells of the basal layer of the epidermis, immediately adjacent to the newly forming dermal bone structures of the fin rays (Laforest et al. 1998). Ectopic expression of shh or bmp2 in the blastema induces excess bone deposition and mispatterning of the regenerate (Quint et al. 2002). The expression of chordin, an inhibitor of BMP signaling, can block these effects, and the Shh signaling inhibitor cyclopamine causes an inhibition of fin outgrowth, implicating both Shh and BMP signaling in the proliferation and/or differentiation of scleroblasts (Quint et al. 2002). Recent studies further define a role for BMP signaling as being required for both blastema cell proliferation as well as bone matrix deposition (Smith et al. 2006). Surprisingly, Smith et al. (2006) describe differential expression of $\operatorname{sox} 9 a / b$, and a recent study by Avaron et al. (2006) shows expression of Indian hedgehog, all known to be expressed by cartilage-forming cells, during fin regeneration (Avaron et al. 2006; Smith et al. 2006). This would not be surprising if we were talking about axial and/or appendicular skeletal elements, which are formed via endochondral ossification, but fin rays are described as dermal bones, which are made via intramembranous ossification (Haas 1962; Geraudie and Landis 1982; Hall and Miyake 2000). Avaron et al. (2006) suggest that the presence of cartilage markers indicates that the dermal fin ray represents an intermediate phenotype between cartilage and bone. Interestingly, sox $9 a$ expression depends on intact BMP signaling, but $s 0 x 9 b$ does not (Smith et al. 2006). Finally, RA receptors are expressed during fin regeneration, and exogenous RA causes bifurcating bones to fuse together, suggesting a role for RA signaling in bone patterning during outgrowth (White et al. 1994).

\section{Positional memory}

Similar to regenerating limbs, amputated fins display "positional memory." That is, they grow back to the correct length, no matter where on the proximodistal 
axis they were amputated, and fins amputated more proximally grow back faster than do fins amputated more distally (Akimenko et al. 1995; Lee et al. 2005). Lee et al. (2005) found that growth rates correlate with position-dependent differences in blastemal length, mitotic index, and expression of FGF signaling target genes. Using transgenic fish in which FGF signaling can be inducibly attenuated, these authors show that the level of FGF signaling determines regenerative growth rate, thus implicating this pathway in instructing positional memory in the fin (Lee et al. 2005). It is known that FGF signaling regulates msxb expression (Poss et al. 2000). It may be through Msxb that positional memory is conferred, considering that the level of expression of msxb depends on where along the proximodistal axis the fin is amputated, with cells of the rapidly proliferating proximal blastema expressing higher levels than the cells of the less rapidly proliferating distal blastema (Akimenko et al. 1995; Lee et al. 2005).

\section{Negative regulators}

While the gradual extinction of a positive regulator of regeneration is one way in which a fin might tell itself to stop growing by a certain point, there are likely additional mechanisms at work. Our recent studies describe a role for $\beta$-catenin-independent Wnt signaling, activated by $W n t 5 b$, as a negative regulator of fin regeneration (Stoick-Cooper et al. 2007). We show that overexpression of Wnt5b in heat-shock transgenic fish inhibits $\beta$-catenin target gene expression and cell proliferation and leads to complete regeneration failure. Most importantly, we show that fish that are homozygous mutants for $w n t 5 b$ regenerate their fins faster than wild type. Because $w n t 5 b$ appears to act to negatively regulate $\beta$-catenin signaling, we postulated that $\beta$-catenin signaling may induce $w n t 5 b$ expression in an effort to regulate itself, and we find that this is, indeed, the case, as inhibition of $\beta$-catenin signaling results in suppression of $w n t 5 b$ expression. These findings lead us to the hypothesis that wnt5b acts in a negative feedback loop to regulate $\mathrm{Wnt} / \beta$-catenin signaling to aid in regrowing the proper size of fin (Stoick-Cooper et al. 2007). Wnt5b is expressed throughout regeneration from very early on, and while it is possible that it might only act to regulate the function of Wnt/ $\beta$-catenin signaling, it may also play other roles that remain to be uncovered.

\section{Summary}

Studies of zebrafish fin regeneration have shown that molecular mechanisms similar to those in limb regeneration are at play. The unique ability to perform forward genetic screens for mutations affecting regeneration has provided genetic proof for the importance of FGF signaling in formation of the WE and subsequent establishment of the blastema. Likewise, Wnt/ $\beta$-catenin signaling is involved in all three phases of regeneration and is sufficient to enhance regenerative outgrowth, while $\beta$-catenin-independent Wnt signaling serves as an unexpected required antagonist of regeneration. The cellular and molecular events that occur during fin regeneration are summarized in Table 1, Figure 2, and Table 2, respectively.

\section{Heart regeneration}

It is not surprising that heart regeneration is a major topic of interest among regeneration enthusiasts. Myocardial infarction (MI) is a leading cause of death worldwide. If one is lucky enough to survive an MI, the damaged area of his/her heart will be scarred permanently, rendering the heart more likely to endure future MIs and
Figure 2. Major signaling events regulating zebrafish fin regeneration. The cartoon combines signals that have been found to be required in vivo or are implicated to be involved by overexpression data. Regeneration occurs in three steps. (1) Wound healing and formation of a specialized WE requires Wnt $/ \beta$-catenin and FGF signaling. Regenerative angiogenesis begins at this stage and requires VEGF signaling. (2) Wnt $\beta$-catenin and FGF signaling pathways are also required for blastema formation. SDF-1 and Wnt5b might act as negative regulators of blastema formation. (3) Wnt/ $\beta$-catenin and FGF signaling are required for regenerative outgrowth. FGF signaling is also required for positional memory. Shh, BMP, and RA all participate in patterning the regenerating bones. Wnt5b acts as a negative regulator of fin outgrowth.

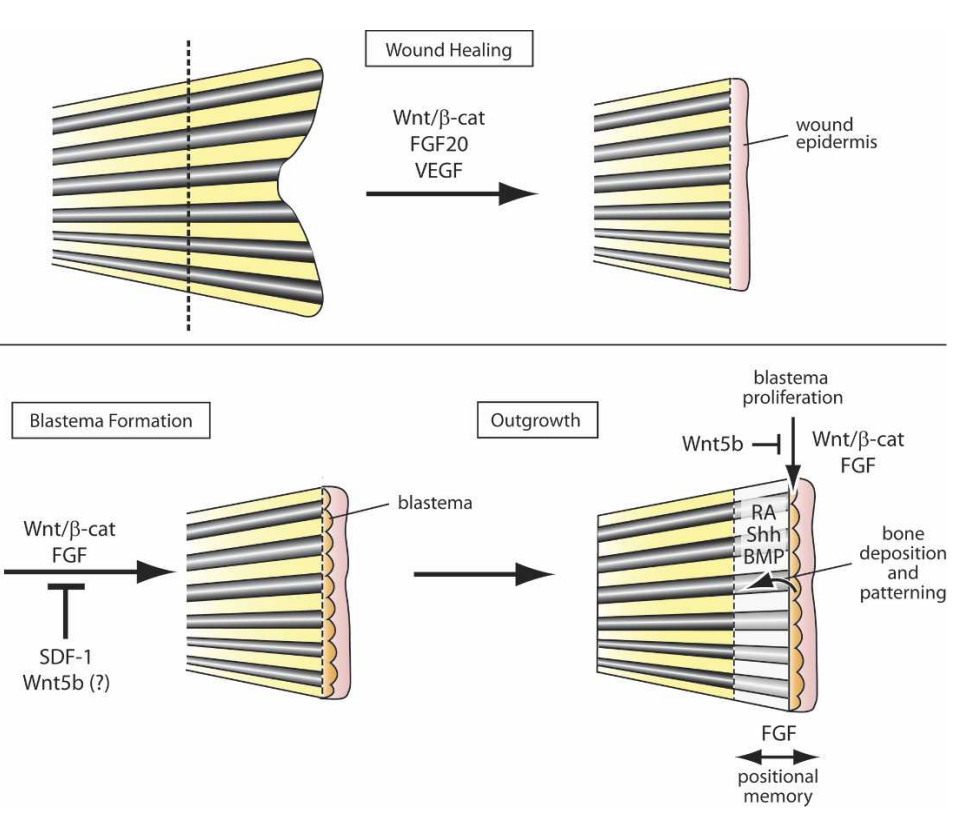


eventually complete organ failure. Therefore, one goal of regenerative medicine is to promote heart repair or regeneration, thereby enhancing the lives of millions of patients.

There are studies that demonstrate some signs of heart regeneration in the newt and axolotl, although the predominant response to resection of the heart is scarring (Becker et al. 1974; Oberpriller and Oberpriller 1974; Neff et al. 1996; Flink 2002). In contrast, zebrafish possess a unique ability to completely regenerate amputated hearts (Poss et al. 2002; Raya et al. 2003; Poss 2006). Immediately after ventricular resection, an erythrocytic clot forms that seals the wound (Poss et al. 2002). Fibrin replaces the clot and instead of becoming collagen-rich scar tissue, as happens in mammals, new cardiomyocytes displace the fibrin and give rise to new cardiac muscle. Although there are few studies that describe this latter process, a recent study from the Poss laboratory (Lepilina et al. 2006) shows that after ventricular resection, regeneration proceeds through two coordinated steps. First, undifferentiated progenitor cells that express genes normally only found in heart precursors during embryogenesis localize to the apical edge of the existing myocardium. Then epicardial tissue surrounding both cardiac chambers rapidly expands to cover the exposed myocardium. Some of these epicardial cells undergo an epithelial-to-mesenchymal transition (EMT), invading the wound and providing new vasculature to regenerating muscle. Functionally, the only signaling pathway that has definitively been shown to be required for this process in vivo is the FGF signaling pathway (Lepilina et al. 2006). When FGF signaling is blocked by expression of a dominant-negative FGF receptor in transgenic fish, epicardial EMT and coronary neovascularization fail, halting regeneration prematurely.

We recently showed in the Wnt/ $\beta$-catenin-responsive transgenic zebrafish reporter line TOPdGFP that Wnt $/ \beta$ catenin signaling is also activated in the same region that Leplilina et al. (2006) found to be rich in cardiac progenitors from 3 to $14 \mathrm{dpa}$, raising the question of what the functional role of Wnt/ $\beta$-catenin signaling may be during heart regeneration (Lepilina et al. 2006; StoickCooper et al. 2007). Another recent study identified two members of the platelet-derived growth factor (PDGF) family to be up-regulated during zebrafish heart regeneration (Lien et al. 2006). Intriguing data suggest that PDGF signaling may be required in vivo during regeneration for DNA synthesis in cardiomyocytes (Lien et al. 2006). Notch1b and deltaC, as well as many other genes, have been shown to be expressed during heart regeneration as well, but future studies are needed to determine the functional involvement of each gene during this process (Raya et al. 2003; Lien et al. 2006).

\section{Summary}

In summary, the field of zebrafish heart regeneration is young, but holds much promise in answering questions about how a heart is naturally optimized to regenerate after damage and may hold many clues as to how to manipulate mammalian hearts to do so as well. The zebrafish heart regenerates via activation of progenitor cells that display an embryonic expression profile. Molecular analysis of heart regeneration has only recently begun and has uncovered an essential role for FGF signaling during later phases of the regenerative process. Other pathways, including Wnt/ $\beta$-catenin and Notch signaling, are known to be activated, but their function has so far not been tested. The cellular and molecular events that occur during heart regeneration are summarized in Tables 1 and 2 .

\section{Liver}

The liver is the only mammalian organ that displays high regenerative capacity, and readily regenerates also in lower vertebrates. After amputation/resection (hepatectomy) of up to $70 \%$ of liver mass, the original size of the organ will be restored within 7-10 d in rats and 3-6 mo in humans (for review, see Taub 2004; Campbell et al. 2006). Similarly, the liver can recover from massive death of cells due to toxins or virus infection. The leftover healthy parts of the liver make up for the lost mass by proliferation, thus the liver regenerates by compensatory growth.

Interestingly, compensatory liver growth can be achieved by several means. In response to amputation, the remaining differentiated cells enter the cell cycle and go through one to two rounds of cell division until the original size of the organ has been replaced (for review, see Fausto 2004; Taub 2004; Fausto et al. 2006). This is a remarkable process, since the differentiated cells of the adult liver are long-lived and normally do not undergo cell division. In addition, the cells do not lose their differentiated phenotype during proliferation, which makes liver regeneration one of the few examples of proliferation of terminally differentiated cells. This property is likely important, since the regenerating liver needs to stay functional during regeneration due to its essential roles in metabolic homeostasis and its function as the main detoxifying organ of the body. Eighty percent of the cells in the adult liver are parenchemal hepatocytes. After partial hepatectomy, most of these hepatocytes in the remaining liver enter the cell cycle quickly, reaching $S$ phase within $12 \mathrm{~h}$ in rats and peaking at $24 \mathrm{~h}$. Other important hepatic cell types-the Kupffer cells (a macrophage that permanently resides in the liver), biliary epithelial cells, and endothelial cells lining the blood vessels-start to proliferate later. Since the various cell types proliferate at different speeds, the organization of the liver is not maintained during regeneration. Rather, hepatocytes form clusters of 10-14 cells that do not resemble normal liver architecture. Thus, the proliferative phase of liver regeneration must be followed by a poorly understood remodeling phase, in which normal organization is re-established.

It is now thought that in addition to regeneration by proliferation of differentiated cells, progenitor cells can also contribute to restoration of liver mass. In particular, it appears that such progenitor cells are the main source 
of regeneration in response to death of hepatic cells caused by virus infection or certain toxic substances (for review, see Fausto 2004; Santoni-Rugiu et al. 2005). While the exact nature of these progenitors, their potential to differentiate into several cell types, and their location in the liver has not been conclusively established, it appears that so-called oval cells act as a progenitor cell type during regeneration (Newsome et al. 2004). These are thought to reside in a defined progenitor cell niche (the canals of Hering in the biliary tree) and have been shown to contribute to differentiation of hepatocytes and biliary cells (Evarts et al. 1987, 1989; Sell 2001; Oh et al. 2002; Yin et al. 2002). Recently, a progenitor cell population distinct from oval cells has been isolated from adult human liver that can differentiate into hepatocytes, and along osteogenic and endothelial fates. Importantly, these cells also participate in liver regeneration when injected into damaged livers (Herrera et al. 2006). Thus, it appears that several progenitor cell populations exist in the adult liver that might play important roles in liver regeneration.

Additionally, it has been shown that adult hepatocytes appear to be able to transdifferentiate into biliary epithelium during repair from injury under conditions in which the proliferative capacity of the biliary cells is compromised (Michalopoulos et al. 2005). Thus, it appears that differentiated hepatocytes possess some cellular plasticity that can assist efficient regeneration.

Quite a lot is known about the extracellular signaling pathways regulating liver regeneration. In fact, compensatory growth of the liver is arguably the best understood regenerative process from a molecular point of view. The success in elucidating the pathways regulating liver regeneration stems from the availability of cell culture models useful for testing the mitogenic activities of signaling factors combined with powerful genetic tools like liver-specific knockouts in mice that address whether a certain pathway is required in vivo. Most of the studies on signaling in liver regeneration have used the hepatectomy model, where differentiated cells respond by proliferation, but it appears that many of the same signals regulate the progenitor-mediated regeneration triggered predominantly by toxins.

\section{Innate immunity and cytokine signaling}

The earliest signals known to be important for triggering liver regeneration are part of the innate immune system. These signals activate Kupffer cells, the macrophages that are resident to the liver, which then produce secondary signals that activate regeneration. Lipopolysaccharide (LPS), which is present in the portal circulation due to its release from the cell walls of bacteria in the gut, is an endotoxin that can trigger strong responses of the innate immune system. Kupffer cells have receptors for LPS, and regeneration is delayed in germ-free mice or mice with a hyposensitivity to LPS (Cornell et al. 1990). The hyposensitivity to LPS is caused by a point mutation in Toll-like receptor 4 (Tlr4), a member of a class of receptors that bind various microbial products (Poltorak et al. 1998). Interestingly however, Tlr4 knockout (KO) mice and mice deficient in other TLR-like receptors show normal liver regeneration. In contrast, mice lacking myeloid differentiation factor 88 (MyD88), an adapter protein that acts downstream from several of these receptors, do not activate cytokines in response to hepatectomy (Seki et al. 2005; Campbell et al. 2006). Thus, although it appears that signaling from TLR-like receptors is important for the earliest triggers of regeneration, it has become doubtful whether LPS itself is the ligand that activates Kupffer cells. In addition to microbial endotoxin-activated signaling, the members of the complement cascade C3a and C5a activate Kupffer cells to stimulate the release of cytokines that then act on hepatocytes and other cell types (Mastellos et al. 2001; Strey et al. 2003).

Activation of this cytokine network happens very fast, within $30 \mathrm{~min}$ post-amputation, and is thought to be required to make hepatocytes competent for cell division. In the normal liver, hepatocytes are quiescent and only minimally respond to potent mitogenic growth factors. Cytokines, on the other hand, are also not sufficient to trigger proliferation, but they appear to make hepatocytes competent to respond to growth factor stimuli, a process called priming. The main cytokines studied are tumor necrosis factor (TNF) and Interleukin-6 (IL-6). TNF receptor- $1 \mathrm{KO}$ mice have several defects after partial hepatectomy, but mice lacking the TNF ligand regenerate normally, indicating that TNF acts redundantly with other ligands that bind the receptor (Fujita et al. 2001; Hayashi et al. 2005). TNF and other ligands of the TNF receptor are thought to activate NF-кB signaling in Kupffer cells, which results in up-regulation of $I L-6$ expression (Kirillova et al. 1999). IL-6 released by Kupffer cells then acts on hepatocytes, where it activates Stat3 and mitogen-activated protein kinase (MAPK) signaling, resulting in modulation of transcription of many target genes (Li et al. 2001).

Interestingly, a TNF-related ligand, TWEAK, has been found to be involved in activation of liver progenitor cells in toxin-induced regeneration, without having an effect on differentiated hepatocytes (Jakubowski et al. 2005). TWEAK is sufficient to stimulate proliferation of oval cells in culture and in vivo, while mice deficient for the TWEAK-receptor Fn14 or mice treated with an antiTWEAK antibody display a reduction in oval cell expansion during toxin-induced regeneration. Thus, in contrast to other cytokines, TWEAK appears to be a specific regulator of progenitor cell-mediated liver regeneration.

Recently, platelet-derived serotonin was shown to be required for mouse liver regeneration (Lesurtel et al. 2006). Besides its function as a neurotransmitter, serotonin is known to act as a hormone with various functions. Platelets (thrombocytes) carry serotonin in the blood and release it at sites of tissue injury. Expression of serotonin receptors in the liver is up-regulated during regeneration, and hepatocyte proliferation after hepatectomy is reduced after chemical inhibition of serotonin receptors and in mice lacking serotonin on platelets. These findings might represent another direct link between the in- 
jury response and regeneration, but at present the timing of serotonin-dependent responses and the cell type that responds to the hormone have not been characterized in detail.

\section{Growth factor signaling}

After priming by cytokines, growth factors drive cell cycle progression of differentiated liver cells during regeneration. Hepatocyte growth factor (HGF) is a potent mitogen for primed hepatocytes, and analysis of mice specifically lacking the HGF receptor $c$-met in hepatocytes confirms that HGF signaling is required for liver regeneration (Borowiak et al. 2004; Huh et al. 2004). The second major class of growth factors regulating hepatic cell proliferation is the ligands of the epidermal growth factor (EGF) receptor, including EGF, TGF $\alpha$, heparinbinding EGF-like growth factor (HB-EGF), and amphiregulin $(\mathrm{AB})$. These factors can induce proliferation of (primed) hepatocytes in vitro and in vivo. Knockout of individual ligands results in a significant deficit in cell proliferation (AR), a delay in replication (HB-EGF), or no detectable defect (TGF $\alpha)$, indicating that these ligands act partially redundantly in liver regeneration (Russell et al. 1996; Berasain et al. 2005; Mitchell et al. 2005). The receptors for both HGF and the EGF family of ligands are receptor tyrosine kinases that activate numerous intracellular signaling pathways, including the Ras-Ref-MEK cascade, PLC $\gamma$, Src, and Akt, resulting in cell proliferation.

Cytokines appear to activate growth factors at least in part via activation of MMPs. In cultured hepatocytes, the cytokine TNF can activate an MMP called TGF $\alpha$-converting enzyme (TACE), resulting in release of TGF $\alpha$ and activation of cell proliferation (Argast et al. 2004). This is relevant in vivo, since mice lacking a specific inhibitor of TACE show elevated levels of TNF protein and earlier entry into S phase after hepatectomy (Mohammed et al. 2004). In addition, the main effect of TNF in priming of hepatocyte proliferation in response to EGF has been shown to be the activation of MMPs, which degrade extracellular matrix components and thus allow proliferation of hepatocytes (Serandour et al. 2005).

\section{Other signals}

Expression of FGF ligands and the FGF receptors 1 and 2 is up-regulated in regenerating liver, indicating that FGF signaling might play a role in regeneration (Evarts et al. 1993; Sturm et al. 2004b). However, mice deficient in Fgf2 display only minor defects in liver regeneration (Sturm et al. 2004b). Interestingly, VEGF, whose expression is up-regulated in Fgf2 KO mice, might compensate for the loss of Fgf2, since chemical inhibition of VEGF signaling in Fgf2 KO mice results in significant impairment of regeneration, while it has no effect in wild-type mice (Sturm et al. 2004a).

Wnt/ $\beta$-catenin signaling has also been suggested to play a role in mammalian liver regeneration. Levels of $\beta$-catenin have been reported to increase within $5 \mathrm{~min}$ after hepatectomy, but decrease below the baseline by 15 min (Monga et al. 2001). Although such a transient increase in $\beta$-catenin levels is unlikely to be sufficient for induction of Wnt target gene expression, studies using antisense morpholino-mediated knockdown of $\beta$-catenin in regenerating rat liver and conditional knockout of $\beta$-catenin in the mouse liver have reported decreased hepatic cell proliferation and suboptimal regeneration (Sodhi et al. 2005; Tan et al. 2006). Since $\beta$-catenin has important functions in cell adhesion, it remains to be seen whether these effects are due to decreased Wnt/ $\beta$ catenin signaling.

\section{Signals that inhibit liver regeneration}

The size of the liver is highly regulated and tuned to the functional needs of the organism. Consequently, liver regeneration needs to stop when the original mass has been reached. The signals that mediate this regulation are poorly understood, but might include TGF $\beta$ and related TGF $\beta$ family members such as activin. TGF $\beta$ acts as a hepatocyte anti-proliferative factor, but although TGF $\beta$ protein is up-regulated during regeneration, hepatocytes become resistant to TGF $\beta$ and can proliferate despite its presence (Koniaris et al. 2003). The TGF $\beta$ family of ligands signals via SMAD proteins, and resistance of hepatocytes to TGF $\beta$ might be partly achieved by up-regulation of the SMAD inhibitors SNON and SKI (Macias-Silva et al. 2002). Notably, inhibitory complexes between SNON, SKI, and activated SMADs decrease after restitution of liver mass. Activin also blocks hepatocyte proliferation and shows decreased signaling during regeneration, when the levels of its receptors are reduced, but receptor levels rebound at termination of regeneration (Date et al. 2000). Importantly, inhibition of activin and TGF $\beta$ signaling by administration of follistatin results in accelerated liver regeneration and increased liver size (Takabe et al. 2003). Thus, signaling through TGF $\beta$ pathways might at least partially regulate the termination of liver regeneration.

\section{Summary}

The liver is the only mammalian organ that regenerates after major loss of tissue, by activation of compensatory growth via proliferation of differentiated hepatocytes or activation of progenitor cells. The cellular events that occur during liver regeneration are summarized in Table 1. Studies of the signals regulating liver regeneration have revealed a major role for immune system-derived signals, in particular cytokines, in triggering proliferation. In addition, several growth factors, including FGF, are required for proliferation. The molecular signals that govern liver regeneration are summarized in Figure 3 and Table 2.

\section{Skeletal muscle}

Skeletal muscle tissue has a high capacity for regeneration. In amphibia, skeletal muscle can regenerate in the 


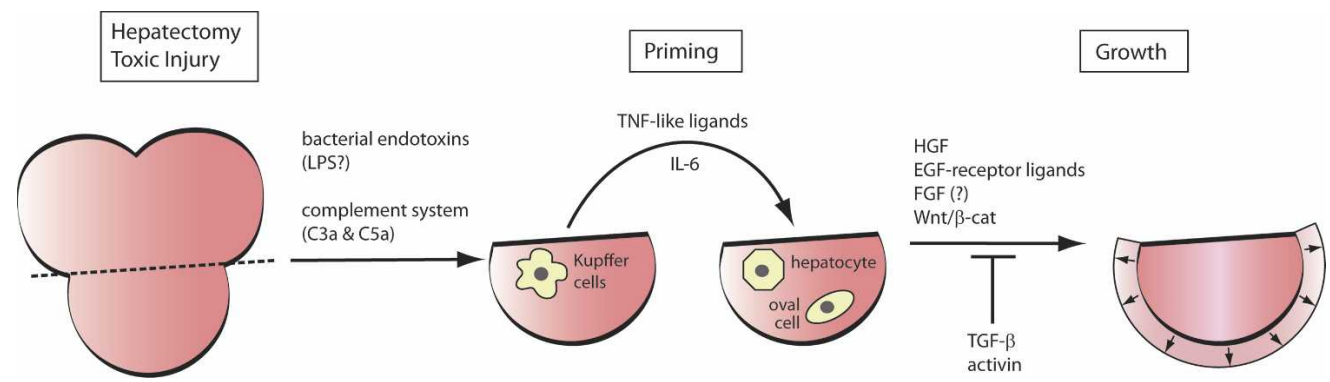

Figure 3. Signals involved in regulation of mammalian liver regeneration. Evidence from in vitro and in vivo data is combined in the cartoon. Liver regeneration occurs in response to toxic injury or partial hepatectomy, which is depicted in the cartoon. Bacterial endotoxins, possibly including LPS, and signals from the innate immune system, in particular the complement components C3a and C5a, might activate resident macrophages in the liver, the Kupffer cells. These secrete cytokines, including IL- 6 and members of the TNF family including TWEAK, which make differentiated hepatocytes competent for proliferation. Mainly in response to toxic injury, but not after hepatectomy, these cytokines also activate progenitor cells, the so-called oval cells. Several growth factors are then implicated in regulating proliferation of primed hepatocytes or oval cells, in particular HGF, members of the EGF family, and FGF. Wnt $\beta$-catenin signaling might also be involved. Members of the TGF $\beta$ family of signaling molecules, in particular activin, act as negative regulators of liver proliferation.

context of a whole regenerating limb or tail. Here, new muscle is formed from progenitor cells of the blastema. In addition, local damage of muscle can be repaired by direct formation of muscle fibers from resident progenitor cells at the site of damage. This type of repair, sometimes called "tissue mode of muscle regeneration," appears to be a universal feature of vertebrates (for review, see Carlson 2003), while muscle regeneration from a blastema in the context of an appendage is a feat only displayed by amphibia. We discussed such epimorphic muscle regeneration in the sections on limb and tail regeneration, and here we will focus on muscle tissue regeneration, which has been most intensely studied in chick, rats, and mice. Many signals involved in muscle regeneration have been identified through a combination of cell culture studies and mouse genetics. One emerging theme from these studies is that many of the signals that regulate muscle formation during embryogenesis are also involved in muscle regeneration.

Repair of muscle is triggered in response to damage of individual muscle fibers due to trauma, ischemia, or toxins, but can, at least in the relatively small rodents and birds, occur even if a whole muscle is explanted, minced into small pieces, and replaced back into the bed of the removed muscle (for review, see Carlson 2003). After injury, cells of the immune system, in particular neutrophils and macrophages, rapidly invade muscle, and there is good evidence that injured muscle actively attracts these cells by production of several chemoattractants (for review, see Tidball 2005). Neutrophils appear to actually increase the damage, by lysing cell membranes via a superoxide-dependent mechanism. Depletion of neutrophils before injury due to ischemia reduces the histologically detectable muscle damage (Korthuis et al. 1988; Kyriakides et al. 1999), and mice with a null mutation of gp $91^{\text {phox }}$, which is required for superoxide generation by neutrophils, do not suffer from membrane lysis after injury (Nguyen and Tidball 2003). Whether such amplification of damage is actually beneficial for efficient regeneration or rather impairs repair is not entirely clear.
On one hand, gp91 phox $\mathrm{KO}$ mice appear to regenerate normally (Nguyen and Tidball 2003), but toxin-induced regeneration is slower in animals whose neutrophils have been depleted by antisera (Teixeira et al. 2003).

Macrophages also rapidly invade injured muscle. They appear to aid in removal of cellular debris by phagocytosis, but can also increase the damage. This was shown in $m d x$ mice, which are mutant for dystrophin and therefore are more susceptible to mechanical damage of the cell membrane during muscle contraction. This leads to muscle degeneration due to membrane lysis and a muscular dystrophy phenotype. Depletion of macrophages in $m d x$ mice results in a significant decrease of muscle cell membrane lysis in vivo (Petrof et al. 1993). In contrast to neutrophils, however, there is more evidence that macrophages have a beneficial role for muscle regeneration. Depletion of macrophages by irradiation impairs muscle regeneration by transplanted myogenic cells, and conditioned media from macrophage cultures increases the rate of proliferation of muscle progenitor cells in vitro (Cantini and Carraro 1995; Massimino et al. 1997; Merly et al. 1999; Cantini et al. 2002). Some candidate molecules mediating these effects are discussed below.

As we have discussed above, during limb and tail regeneration of urodele amphibia, differentiated muscle fibers dedifferentiate, and a sizable fraction of the progenitor cells of the blastema is thought to be produced by this mechanism. In contrast, muscle repair by the tissue mode both in urodeles and in amniotes does not appear to involve dedifferentiation. Rather, resident muscle progenitor cells, called satellite cells, that reside between the muscle fiber surface and the overlying basement membrane are activated to proliferate and either fuse with damaged, but still living fibers, or differentiate into new multinucleated myofibers by fusing with each other (Wagers and Conboy 2005). Several cell types displaying characteristics of hematopoietic progenitor cells have also been shown to have myogenic potential. Genetically marked bone marrow grafts and even individual hematopoietic stem cells can contribute to regenerating 
myofibers, and a population of muscle-resident cells expressing the hematopoietic lineage marker CD45 has also been shown to be myogenic (Ferrari et al. 1998; Gussoni et al. 1999; LaBarge and Blau 2002; Camargo et al. 2003; Corbel et al. 2003; Polesskaya et al. 2003; Sherwood et al. 2004). While these findings are still very exciting due to their therapeutic promise, the prevalent view today is that, under normal physiological conditions, satellite cells are the only relevant source of regenerating skeletal muscle and that the contribution of other cells is negligible (Partridge 2004; Wagers and Conboy 2005).

\section{Cytokine signaling}

Macrophages secrete proteins that can stimulate muscle progenitor cell proliferation, and it appears that some of the same cytokines that regulate liver regeneration are at play here as well. The cytokines IL-6, leukemia inhibitory factor (LIF), and TGF $\alpha$ can stimulate muscle progenitor proliferation and inhibit their differentiation in culture (Austin and Burgess 1991; Austin et al. 1992; Jo et al. 2005), but $I L-6 \mathrm{KO}$ mice have no muscle regeneration defect (Warren et al. 2002), making it unclear at present whether these cytokines play a role in vivo. TNF receptor double-knockout mice and mice treated with neutralizing anti-TNF $\alpha$ antibody show defects in expression of muscle differentiation markers and in formation of new muscle fibers (Warren et al. 2002; Chen et al. 2005), indicating that TNF $\alpha$ signaling has a positive role in muscle regeneration. However, loss of $T N F \alpha$ and double knockout of $T N F \alpha$ with its homolog $L T \alpha$ do not impair muscle regeneration (Collins and Grounds 2001). Furthermore, overexpression of TNF $\alpha$ in vivo results in inhibition of muscle regeneration (Coletti et al. 2005). Thus, the role of TNF $\alpha$ in muscle repair is complex, and it might have positive and negative affects depending on the injury model and the stage of the injury.

Interestingly, the TNF ligand TWEAK, which is required for progenitor cell activation during liver regeneration (see above), appears to have a positive role in skeletal muscle regeneration as well. TWEAK promotes proliferation and inhibits differentiation of muscle precursors in culture, and mice deficient in the TWEAK receptor Fn14 display delayed muscle fiber regeneration (Girgenrath et al. 2006). Macrophages are the likely source of the TWEAK signal. In summary, several cytokines are involved in regulation of muscle regeneration, but further studies are required to clarify whether these act as triggers of regeneration.

\section{Growth factor signaling}

FGF ligands are able to stimulate the proliferation and suppress the differentiation of muscle progenitors in culture (for review, see Husmann et al. 1996). However, FGF6 overexpression in vivo was shown to be sufficient to both induce muscle proliferation and accelerate differentiation (Armand et al. 2003, 2005). Contradictory results have been published about the in vivo role of FGF6 in muscle regeneration. One group reported that Fgf6 KO mice showed reduction of satellite cell activation after injury and impaired regeneration (Floss et al. 1997), but another group found no muscle regeneration defects in independently created Fgf6 KO mice (Fiore et al. 2000). Yet another group found that differentiation of muscle progenitors was actually accelerated in Fgf6 KO mice (Armand et al. 2005). These striking discrepancies are unresolved at this time, but could be due to different gene targeting strategies, genetic backgrounds, and injury models. Sources for FGF ligands in vivo are both macrophages and satellite cells, but further studies are needed to clarify the role of FGF signaling in muscle regeneration.

Insulin-like growth factors (IGFs) stimulate proliferation of muscle progenitor cells, but subsequently also induce their differentiation (for review, see Mourkioti and Rosenthal 2005). These effects are achieved via activation of different intracellular pathways by the same IGF type I receptor: MAPK signaling induces proliferation, while phosphatidylinositol 3-kinase (PI3K) signaling causes differentiation. While loss-of-function evidence for an in vivo requirement of IGF signaling in muscle regeneration is not available, targeted overexpression of IGF in muscle has spectacular beneficial effects on regeneration after injury, muscle degeneration in muscular dystrophy $m d x$ model mice, and on agerelated muscular atrophy and diminished regenerative capacity (Musaro et al. 2001; Barton et al. 2002; Rabinovsky et al. 2003).

\section{Notch signaling}

Notch signaling is induced in activated satellite cells $2 \mathrm{~d}$ after injury both in culture and in vivo (Conboy and Rando 2002). In several systems, asymmetric cell division of progenitor cells results in asymmetric inheritance by the daughters of the protein Numb, which inhibits Notch signaling (Roegiers and Jan 2004). Thus, different levels of Notch signaling exist in the daughter cells, causing the daughters to adopt different cell fates. Interestingly, Conboy and Rando (2002) found that activated satellite cells during muscle regeneration also show asymmetric Numb expression. In a myofiber explant system, cells with low Numb levels expressed markers of a less committed muscle phenotype, and overexpression of Numb resulted in down-regulation of these markers. Conversely, expression of constitutively active Notch receptor caused inhibition of differentiation markers and increased proliferation of the progenitors in culture (Conboy and Rando 2002). Importantly, inhibition of Notch signaling in vivo impaired muscle regeneration (Conboy et al. 2003). Thus, it appears that active Notch signaling induces proliferation of satellite cells and keeps them in an uncommitted state and that asymmetric distribution of Numb during cell division results in inhibition of Notch signaling in one daughter, which proceeds to differentiate along the myogenic lineage. Notch signal transduction in activated satellite 
cells appears to be triggered by up-regulation of the ligand Delta in satellite cells themselves and in muscle fibers adjacent to the damage (Conboy et al. 2003). Upregulation of Delta and activation of Notch signaling are diminished in old mice, whose satellite cells proliferate less in response to injury, resulting in reduced efficacy of regeneration. Intriguingly, forced activation of Notch signaling at the site of injury was sufficient to improve muscle regeneration in old mice, rendering it similar to that of young mice (Conboy et al. 2003).

\section{Wnt $/ \beta$-catenin signaling}

Wnt/ $\beta$-catenin signaling has been shown to be involved in myogenic commitment of nonsatellite progenitor cells. As we have discussed above, the relevance of such cells for muscle regeneration under nonexperimental conditions is being debated. Nevertheless, the identification of signaling pathways regulating the fate of such cells might be of therapeutic relevance. Cells expressing the hematopoietic cell surface markers Scal and CD45 were found to be present in muscle and to proliferate in response to injury (Polesskaya et al. 2003). Sca $1^{+} / \mathrm{CD} 45^{+}$ cells from uninjured muscle were not myogenic in culture, but cells isolated from regenerating muscle did differentiate along a myogenic fate. Expression of several Wnt ligands was found to be up-regulated in regenerating muscle, and $\beta$-catenin stabilization, indicative of Wnt/ $\beta$-catenin signaling, occurred in $\mathrm{Scal}^{+} / \mathrm{CD} 45^{+}$cells during regeneration. Coculture with Wnt-expressing cells was sufficient to induce myogenic differentiation of $\mathrm{Scal}^{+} / \mathrm{CD} 45^{+}$cells from uninjured muscle. Furthermore, inhibition of Wnt signaling by injection of the secreted Wnt antagonists sFRP2 and sFRP3 reduced the proliferation and myogenic commitment of $\mathrm{Scal}^{+} / \mathrm{CD} 45^{+}$cells in regenerating muscle.

\section{Signals that inhibit muscle regeneration}

Satellite cells are not only the source of regenerating muscle fibers following injury, but they also create additional muscle during muscle growth; for example, in response to exercise. Consequently, it is not unexpected that similar mechanisms regulate muscle regeneration and muscle growth. Tissue size has long been speculated to be under negative control of secreted factors that are produced by the tissue and circulate through the body (for review, see Lee 2004). Myostatin, a member of the TGF $\beta$ family of signaling molecules, acts as such a negative regulator of tissue growth, and it does so specifically for muscle. Myostatin is exclusively expressed by skeletal muscle in adult mammals, and present in muscle of other vertebrates as well (for review, see Lee 2004). Overexpression in adult mice causes a wasting syndrome characterized by loss of muscle and adipose tissues (Zimmers et al. 2002). Intriguingly, knockout of myostatin in mice results in dramatic and widespread increases of muscle mass, and a natural occurring myostatin mutation produces a particularly beefy breed of cattle (Grobet et al. 1997; McPherron et al. 1997). Muscle mass is increased due to a combination of increased number and size of muscle fibers. Myostatin-deficient muscle contains an increased number of satellite cells, and a higher fraction of these proliferate in vivo (McCroskery et al. 2003). Gain- and loss-of-function experiments show that Myostatin inhibits the G1-to-S progression of satellite cells and thus maintains their quiescent status via regulation of p21, a Cdk inhibitor (McCroskery et al. 2003).

Importantly for the topic of this review, muscle regeneration after injury is enhanced in myostatin knockout mice (McCroskery et al. 2005). Interestingly, this appears to be not only due to increased activation of satellite cells, but also due to accelerated migration of satellite cells and macrophages to the injury. Furthermore, inflammation ceases more rapidly in myostatin-deficient mice. Thus, Myostatin is an important negative regulator of muscle regeneration.

\section{Summary}

Similar to liver regeneration, immune system-derived signals have an important role in skeletal muscle regeneration by activating muscle progenitor cell proliferation. While the in vivo roles of FGF signaling are somewhat unclear, Notch signaling has clearly been shown to be essential and sufficient to enhance muscle regeneration. Wnt $/ \beta$-catenin signaling is required for activation of cells of hematopoietic character to become myogenic, but a role for Wnt signaling in activation of satellite cells that are the predominant source for new muscle has not been described. The cellular and molecular events that occur during muscle regeneration are summarized in Table 1, Figure 4, and Table 2, respectively.

\section{Common themes in molecular regulation of regeneration}

While the scale, the complexity, and the cellular mechanisms of regeneration of different organs and structures are obviously quite different, some common principles in their molecular regulation can be identified.

In all vertebrates, activation of the innate immune system is an early reaction to injury. Consequently, signals regulating the immune response are also good candidates for triggers of regenerative processes. Indeed, both in skeletal muscle and liver regeneration, the immune system provides important signals during early phases of the regenerative processes. Similar cytokines, including IL-6 and ligands of the TNF receptor, secreted by cells of the immune system, are implicated in activation of cell proliferation. In particular, the cytokine TWEAK has been shown to be required for progenitor cell proliferation in regenerating liver and muscle. Whether cytokine signaling is also involved in the regulation of heart regeneration has, to our knowledge, not been tested. Likewise, very little is known about the role of cytokine signaling in epimorphic regeneration of appendages. The complement components $\mathrm{C} 3$ and $\mathrm{C} 5$, which are impli- 


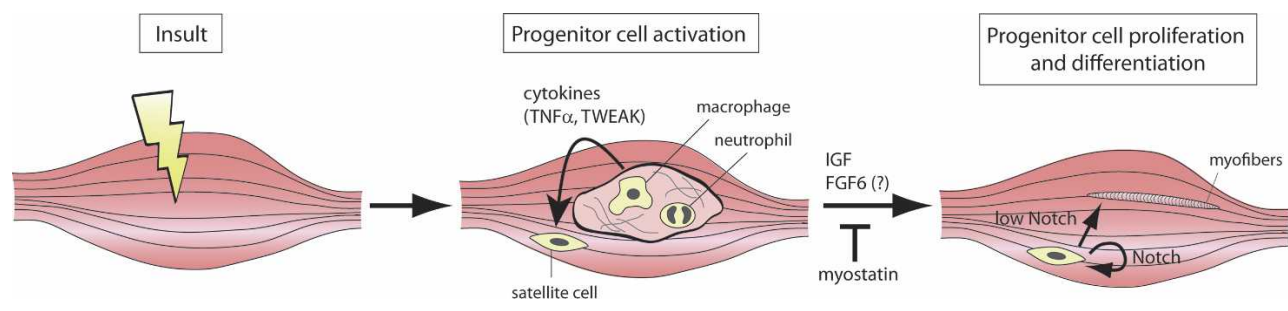

Figure 4. Signaling during skeletal muscle regeneration. Many types of insult can cause local damage and degeneration of muscle fibers. The damaged area is rapidly invaded by macrophages and neutrophils, which secrete cytokines, including TNF $\alpha$ and TWEAK, that activate muscle satellite cells, a population of progenitor cells resident to the muscle. Subsequent proliferation of satellite cells is regulated by IGF and FGF signaling. Satellite cells are thought to renew themselves when Notch signaling is high, while low Notch signaling results in differentiation of satellite cells to new muscle fibers.

cated as triggers of liver regeneration, have been shown to be expressed in specific domains during newt limb and lens regeneration (Kimura et al. 2003), but their functional involvement has not been tested. Interestingly, the chemokine SDF-1 was proposed to be a negative regulator of zebrafish fin regeneration.

Newts appear to have adopted the blood-clotting factor thrombin as an essential signal regulating dedifferentiation and proliferation of cells during muscle and lens regeneration. Thrombin induces cell cycle re-entry of cultured newt myotubes and is activated selectively on the dorsal margin of the iris, which after injury of the lens can dedifferentiate and replace the lens (Imokawa and Brockes 2003; Imokawa et al. 2004). If thrombin activity in the eye is blocked, lens regeneration is impaired. It is noteworthy that newts and the Japanese freshwater fish Misgumus are the only vertebrate species known to be able to regenerate their lenses, while even axolotls, which are otherwise champion regenerators, are incapable of doing so (for review, see Godwin and Brockes 2006). Similarly, muscle dedifferentiation, which thrombin appears to be involved in, might be quite an exceptional feat, only found in urodele amphibians. Therefore, it will be very interesting to test whether the employment of thrombin in regulation of regeneration is a specialized adaptation of newts or important in other organisms and regenerating systems as well.

A comparison of signals known to regulate cell proliferation and specification in different regenerating systems reveals that FGF signaling is implicated in almost all of them. FGFs have several essential roles during epimorphic regeneration of urodele limbs, anuran tails, and fish fins and in regulating WE formation, blastema formation and proliferation, and positional memory. FGF signaling is also required for zebrafish heart regeneration and is implicated in the regulation of cell proliferation and differentiation in regenerating skeletal muscle and mammalian liver, although clarification of its in vivo role in muscle and liver awaits further loss-of-function data. Nevertheless, it is remarkable that FGFs appear to be universal regulators of regeneration, despite the different cellular mechanisms driving regeneration of these systems and the different cell types being regenerated.

Likewise, Wnt/ $\beta$-catenin signaling appears to be in- volved in many regenerative processes as well. It is one of the first signals known to be activated during zebrafish fin and heart regeneration, is required for correct WE patterning in fins and amphibian limbs, and for blastema formation and proliferation in fins. In addition, $\beta$-catenin signaling appears to have a role in liver regeneration and can activate CD45-positive progenitor cells during skeletal muscle regeneration.

In summary, while our knowledge of the signaling pathways controlling different regenerative processes is still sketchy, it is already clear that there is significant overlap in the pathways involved. However, it is likely that the precise function of these signals in different regenerating systems is as diverse as the cellular events happening. Future research will undoubtedly increase the list of common players, but will also reveal differences in their function in different systems.

\section{Lessons for regenerative medicine}

One goal of regenerative medicine is to identify cells, typically progenitor or stem cells, that, when introduced into the injured organ, will stimulate regeneration. An alternative goal is to identify small molecules that will stimulate an organism's own endogenous progenitor cells to promote regeneration. Cell transplant approaches are already moderately successful in improving heart function and skeletal muscle regeneration after experimental injury in mice (for review, see Krampera et al. 2006; Mimeault and Batra 2006; Rubart and Field 2006a,b), and small molecule therapies have been shown to enhance hematopoietic progenitor cell function (Trowbridge et al. 2006). As we discussed in the section on skeletal muscle regeneration, some of these interventions take advantage of the fact that cell types that appear not to play a role in physiological repair processes can nevertheless be of therapeutic value. We will not review such approaches further, but want to summarize attempts at improving regenerative processes that make use of the accumulating knowledge about molecular mechanisms regulating these regenerative processes.

While we have learned quite a bit about the molecular mechanisms and the signaling pathways regulating regenerative processes, we do not quite understand why some tissues and organs regenerate well, while others do 
not. Furthermore, why salamanders and fish are able to form blastemas and regenerate complex structures, while we cannot, is not only difficult to accept, but is also not well understood. A common belief is that regenerative capacity is elevated in lower animals but has diminished in higher ones. However, a more thorough review of the regenerative potential across the animal kingdom reveals that also some "primitive" forms do not regenerate, while close relatives do. For example, some annelids can regenerate the whole body from small fragments, while similarly complex nematodes do not regenerate at all (for review, see Slack 2007). Likewise, urodele amphibians (salamanders) are the champions of vertebrate regeneration, while anuran amphibians have significantly lower regenerative capability. It thus appears that organism complexity is a rather poor predictor for regenerative capacity. Regeneration can be considered a "pristine" quality of all tissues and structures and not a specific evolutionary adaptation of a few organisms and organs. However, this quality is easily lost during evolution and thus appears to carry some evolutionary cost. Yet, from this point of view, it appears reasonable to assume that the basic machinery necessary for regeneration still exists in human organs and that it might be the triggers of regeneration that are missing.

In support of this view, it has been shown that terminally differentiated mouse muscle cells in culture can be stimulated to dedifferentiate-which salamander muscle cells do during limb regeneration-when treated with extracts from salamander regenerating limbs (McGann et al. 2001). Similarly, the diminished regenerative potential of skeletal muscle in old mice can be reversed by joining their circulatory systems with those of young mice (Conboy et al. 2005). Such heterochronic parabiosis restores the activation of Notch signaling in regenerating muscle and the proliferation of satellite cells. Thus, extracellular factors exist that can trigger regeneration in systems that normally do not regenerate. Triggering spectacular regenerative events-like limb regeneration-in humans is a distant goal of regenerative medicine, but manipulation of several factors has been found to improve certain aspects of regeneration.

Most differentiated vertebrate cells withdraw from the cell cycle, which requires the tumor suppressor protein $\mathrm{Rb}$ that inhibits expression of genes needed for cell cycle entry. While normal-cycling cells can inactivate $\mathrm{Rb}$ by phosphorylation and thus enter the cell cycle, differentiated cells such as mammalian muscle do not respond to growth stimuli (like serum in culture), since the kinases that normally phosphorylate $\mathrm{Rb}$ appear to be inhibited. In salamanders, however, skeletal muscle cells and cardiomyocyte cells re-enter the cell cycle in response to serum in culture, and they do so by phosphorylating and thereby inhibiting the $\mathrm{Rb}$ protein (Tanaka et al. 1997; Bettencourt-Dias et al. 2003). Thus, the retained ability to regulate $\mathrm{Rb}$ phosphorylation might be one explanation for the plasticity and regenerative capacity of differentiated salamander cells. Indeed, $R b$-deficient mouse muscle cells can be stimulated to re-enter the cell cycle in response to serum (Schneider et al. 1994), and mouse differentiated post-mitotic auditory hair cells likewise re-enter the cell cycle by induced deletion of $R b$ (Sage et al. 2005).

Expression of Msx homeobox proteins is a hallmark of the blastemas in regenerating amphibian and fish appendages and tails and is also induced in regenerating zebrafish heart. It is thus conceivable that mammals lack the ability to regenerate these structures due to a failure to activate Msx expression. In support of this hypothesis, forced overexpression of Msx1 in cultured mammalian muscle cells has been shown to cause loss of differentiation markers and fragmentation into mononucleated cells (Odelberg et al. 2000). These dedifferentiated cells could be induced to differentiate along chondrogenic, adipogenic, myogenic, and osteogenic lineages. While the importance for dedifferentiation of differentiated cells during regenerative processes is disputed, these results point to the possibility of improving mammalian regeneration by adding factors that regulate regeneration in lower vertebrates.

\section{Overexpression of signaling molecules can improve regeneration}

The identification of signaling factors and pathways that positively regulate regeneration has prompted efforts to augment regeneration by overactivating these signaling pathways. Intriguingly, in many cases, regeneration can be enhanced by such manipulations or, more rarely, even triggered in systems that normally do not regenerate.

As described above, FGF signaling plays essential roles in blastema-mediated regeneration of amphibian and fish appendages. Intriguingly, implantation of beads soaked with FGF10 has been reported to be sufficient to reactivate regeneration in Xenopus limbs at later stages of development where limbs have lost their regenerative capacity (Yokoyama et al. 2001). More dramatically, FGF2-soaked beads can stimulate embryonic chick limb buds, which do not regenerate, to regenerate digit-like structures (Taylor et al. 1994). Thus, activation of FGF signaling holds the promise of improving the regenerative capacity of nonregenerating appendages.

As discussed above, Notch signaling is required for skeletal muscle regeneration in mammals, and forced activation of Notch signaling in injured muscle improves regeneration in old mice (Conboy et al. 2003). Similarly, targeted overexpression of IGF in skeletal muscle improves muscle regeneration in response to injury, betters the phenotype of a muscle dystrophy mouse model, and enhances the regenerative capacity of old mice (Musaro et al. 2001; Barton et al. 2002; Rabinovsky et al. 2003). Systemic IGF overexpression even triggers heart muscle regeneration in response to heart failure in mice (N. Rosenthal, pers. comm.). Intriguingly, it has recently been shown that combining FGF1 stimulation and inhibition of p38 MAPK can induce mitosis of cardiomyocytes in vivo after MI in rats, reduces scarring, and improves heart function (Engel et al. 2006).

We and others have recently shown that Wnt $\beta$ catenin signaling is required for zebrafish and sala- 
mander fin and limb regeneration (Kawakami et al. 2006; Stoick-Cooper et al. 2007). We found that transient activation of $\beta$-catenin signaling by overexpression of Wnt8 was sufficient to increase proliferation in the regenerating zebrafish fin, but did not augment overall regeneration. In contrast, prolonged increase of $\beta$-catenin signaling in fish heterozygous for a loss-of-function mutation of axin1, a negative regulator of $\beta$-catenin signaling, resulted in accelerated regeneration (Stoick-Cooper et al. 2007). Similarly, Kawakami et al. (2006) found that overexpression of constitutively active $\beta$-catenin can rescue fin regeneration in a fish line that is mutant in an as-yetunidentified gene causing variable fin regeneration defects. Furthermore, constitutively active $\beta$-catenin could induce, albeit at low frequency, partial regeneration in developing Xenopus hindlimbs at a stage at which untreated limbs did not regenerate (Kawakami et al. 2006). It is noteworthy that Wnt $/ \beta$-catenin signaling is strongly up-regulated during zebrafish heart regeneration (StoickCooper et al. 2007); thus, manipulation of Wnt signaling has the potential to be beneficial for regenerative therapies.

It is obvious that attempts to augment regeneration by overactivation of potent signaling molecules, which regulate proliferation and specification of many cell types and some of which, like Wnt/ $\beta$-catenin signaling, are involved in tumor formation, will have to deal with the issue of unwanted side effects (e.g., cancer). In this regard, it is encouraging that overactivation of $\mathrm{Wnt} / \beta$ catenin signaling in zebrafish regeneration does not appear to induce mispatterning or cancerous overgrowth (Kawakami et al. 2006; Stoick-Cooper et al. 2007). However, it is possible that a system with high regenerative capacity, like a fish fin, is adapted to limit such side effects, but attempts to induce regeneration in a normally nonregenerating organ might be more prone to such problems.

\section{Interference with signaling molecules can augment regeneration}

Regenerative processes need to be tightly regulated to avoid overgrowth, mispatterning, and tumor formation. A few signals that negatively regulate regeneration have been identified. From a therapeutic standpoint, these are very interesting, since it is typically easier to interfere with the function of a gene than to enhance it.

Myostatin is a highly specific inhibitor of muscle growth (see above), and mice lacking myostatin display improved skeletal muscle regeneration (McCroskery et al. 2005). Furthermore, administration of Myostatinneutralizing antibodies increases muscle mass and muscle strength in $M d x$ mice, which serve as a model for Duchenne muscular dystrophy (Bogdanovich et al. 2002). Thus, myostatin is an excellent candidate for therapeutic intervention in degenerative muscle diseases and muscle wasting syndromes.

We found that Wnt5, likely activating a $\beta$-catenin-independent signaling pathway, acts as an inhibitor of zebrafish fin regeneration (Stoick-Cooper et al. 2007).
Thus, fish mutant for one of the two wnt5 paralogs, $w n t 5 b$, exhibit faster fin regeneration. Wnt5 has been shown to act as an inhibitor of Wnt/ $\beta$-catenin signaling in several systems, including the fish fin (Stoick-Cooper et al. 2007), indicating that it might interfere with fin regeneration by inhibiting $\beta$-catenin signaling. It will be interesting to test whether $\beta$-catenin-independent Wnt signaling is active in other regenerative systems and whether its activity correlates with regenerative capacity.

\section{The future of regenerative medicine}

The promise of regenerative medicine lies in part in culturing progenitor and stem cells in vitro and differentiating them into specific cell types suitable for implanting into patients as cell-based therapies. Another hope is that small molecules may stimulate a patient's own progenitor cells to assist in a regenerative response. A third strategy is to grow organs and tissues in vitro for eventual transplantation into patients. All three of these strategies are showing promise, and all will benefit from continued studies of regeneration in model organisms.

\section{Acknowledgments}

We thank Jonathan Slack, Bruce Carlson, Jeremy Brockes, Elly Tanaka, Ken Poss, and Karen Echeverri for helpful discussions; Hitoshi Yokoyama for critical reading of the manuscript; and Katrin Bergmann for help with the figures. C.S.C. is a recipient of an NIH-funded Cardiovascular Pathology Training Grant; R.T.M. is an investigator of the Howard Hughes Medical Institute and receives grants from the National Institutes of Health; and G.W. is funded by the Collaborative Research Center 655 of the Deutsche Forschungsgemeinschaft.

\section{References}

Akimenko, M.A., Johnson, S.L., Westerfield, M., and Ekker, M. 1995. Differential induction of four msx homeobox genes during fin development and regeneration in zebrafish. Development 121: 347-357.

Akimenko, M.A., Mari-Beffa, M., Becerra, J., and Geraudie, J. 2003. Old questions, new tools, and some answers to the mystery of fin regeneration. Dev. Dyn. 226: 190-201.

Allan, C.H., Fleckman, P., Fernandes, R.J., Hager, B., James, J., Wisecarver, Z., Satterstrom, F.K., Gutierrez, A., Norman, A., Pirrone, A., et al. 2006. Tissue response and Msxl expression after human fetal digit tip amputation in vitro. Wound Repair Regen. 14: 398-404.

Argast, G.M., Campbell, J.S., Brooling, J.T., and Fausto, N. 2004. Epidermal growth factor receptor transactivation mediates tumor necrosis factor-induced hepatocyte replication. I. Biol. Chem. 279: 34530-34536.

Armand, A.S., Launay, T., Pariset, C., Della Gaspera, B., Charbonnier, F., and Chanoine, C. 2003. Injection of FGF6 accelerates regeneration of the soleus muscle in adult mice. Biochim. Biophys. Acta 1642: 97-105.

Armand, A.S., Pariset, C., Laziz, I., Launay, T., Fiore, F., Della Gaspera, B., Birnbaum, D., Charbonnier, F., and Chanoine, C. 2005. FGF6 regulates muscle differentiation through a calcineurin-dependent pathway in regenerating soleus of 
adult mice. J. Cell. Physiol. 204: 297-308.

Austin, L. and Burgess, A.W. 1991. Stimulation of myoblast proliferation in culture by leukaemia inhibitory factor and other cytokines. J. Neurol. Sci. 101: 193-197.

Austin, L., Bower, J., Kurek, J., and Vakakis, N. 1992. Effects of leukaemia inhibitory factor and other cytokines on murine and human myoblast proliferation. J. Neurol. Sci. 112: 185191.

Avaron, F., Hoffman, L., Guay, D., and Akimenko, M.A. 2006. Characterization of two new zebrafish members of the hedgehog family: Atypical expression of a zebrafish Indian hedgehog gene in skeletal elements of both endochondral and dermal origins. Dev. Dyn. 235: 478-489.

Barton, E.R., Morris, L., Musaro, A., Rosenthal, N., and Sweeney, H.L. 2002. Muscle-specific expression of insulin-like growth factor I counters muscle decline in $\mathrm{mdx}$ mice. J. Cell Biol. 157: 137-148.

Bayliss, P.E., Bellavance, K.L., Whitehead, G.G., Abrams, J.M., Aegerter, S., Robbins, H.S., Cowan, D.B., Keating, M.T., O'Reilly, T., Wood, J.M., et al. 2006. Chemical modulation of receptor signaling inhibits regenerative angiogenesis in adult zebrafish. Nat. Chem. Biol. 2: 265-273.

Becerra, J., Junqueira, L.C., Bechara, I.J., and Montes, G.S. 1996. Regeneration of fin rays in teleosts: A histochemical, radioautographic, and ultrastructural study. Arch. Histol. Cytol. 59: $15-35$.

Beck, C.W., Christen, B., and Slack, J.M. 2003. Molecular pathways needed for regeneration of spinal cord and muscle in a vertebrate. Dev. Cell 5: 429-439.

Beck, C.W., Christen, B., Barker, D., and Slack, J.M. 2006. Temporal requirement for bone morphogenetic proteins in regeneration of the tail and limb of Xenopus tadpoles. Mech. Dev. 123: 674-688.

Becker, R.O., Chapin, S., and Sherry, R. 1974. Regeneration of the ventricular myocardium in amphibians. Nature 248: $145-147$.

Berasain, C., Garcia-Trevijano, E.R., Castillo, J., Erroba, E., Lee, D.C., Prieto, J., and Avila, M.A. 2005. Amphiregulin: An early trigger of liver regeneration in mice. Gastroenterology 128: 424-432.

Bettencourt-Dias, M., Mittnacht, S., and Brockes, J.P. 2003. Heterogeneous proliferative potential in regenerative adult newt cardiomyocytes. J. Cell Sci. 116: 4001-4009.

Bogdanovich, S., Krag, T.O., Barton, E.R., Morris, L.D., Whittemore, L.A., Ahima, R.S., and Khurana, T.S. 2002. Functional improvement of dystrophic muscle by myostatin blockade. Nature 420: 418-421.

Borgens, R.B. 1982. Mice regrow the tips of their foretoes. Science 217: 747-750.

Borowiak, M., Garratt, A.N., Wustefeld, T., Strehle, M., Trautwein, C., and Birchmeier, C. 2004. Met provides essential signals for liver regeneration. Proc. Natl. Acad. Sci. 101: 10608-10613.

Bosco, L. 1979. Expression of regenerative capacity of caudal spinal cord during the larval development of Xenopus laevis. Acta Embryol. Exp. (Palermo) 3: 275-285.

Brockes, J.P. 1997. Amphibian limb regeneration: Rebuilding a complex structure. Science 276: 81-87.

Brockes, J.P. and Kumar, A. 2002. Plasticity and reprogramming of differentiated cells in amphibian regeneration. Nat. Rev. Mol. Cell Biol. 3: 566-574.

Call, M.K. and Tsonis, P.A. 2005. Vertebrate limb regeneration. Adv. Biochem. Eng. Biotechnol. 93: 67-81.

Camargo, F.D., Green, R., Capetanaki, Y., Jackson, K.A., and Goodell, M.A. 2003. Single hematopoietic stem cells generate skeletal muscle through myeloid intermediates. Nat.
Med. 9: 1520-1527.

Campbell, J.S., Riehle, K.J., Brooling, J.T., Bauer, R.L., Mitchell, C., and Fausto, N. 2006. Proinflammatory cytokine production in liver regeneration is Myd88-dependent, but independent of Cd14, Tlr2, and Tlr4. J. Immunol. 176: 2522-2528.

Cantini, M. and Carraro, U. 1995. Macrophage-released factor stimulates selectively myogenic cells in primary muscle culture. J. Neuropathol. Exp. Neurol. 54: 121-128.

Cantini, M., Giurisato, E., Radu, C., Tiozzo, S., Pampinella, F., Senigaglia, D., Zaniolo, G., Mazzoleni, F., and Vitiello, L. 2002. Macrophage-secreted myogenic factors: A promising tool for greatly enhancing the proliferative capacity of myoblasts in vitro and in vivo. Neurol. Sci. 23: 189-194.

Carlson, B.M. 2003. Muscle regeneration in amphibians and mammals: Passing the torch. Dev. Dyn. 226: 167-181.

Chen, S.E., Gerken, E., Zhang, Y., Zhan, M., Mohan, R.K., Li, A.S., Reid, M.B., and Li, Y.P. 2005. Role of TNF- $\alpha$ signaling in regeneration of cardiotoxin-injured muscle. Am. I. Physiol. Cell Physiol. 289: C1179-C1187.

Chen, Y., Lin, G., and Slack, J.M. 2006. Control of muscle regeneration in the Xenopus tadpole tail by Pax7. Development 133: 2303-2313.

Christen, B. and Slack, J.M. 1997. FGF-8 is associated with anteroposterior patterning and limb regeneration in Xenopus. Dev. Biol. 192: 455-466.

Christensen, R.N., Weinstein, M., and Tassava, R.A. 2001. Fibroblast growth factors in regenerating limbs of Ambystoma: Cloning and semi-quantitative RT-PCR expression studies. J. Exp. Zool. 290: 529-540.

Christensen, R.N., Weinstein, M., and Tassava, R.A. 2002. Expression of fibroblast growth factors 4, 8, and 10 in limbs, flanks, and blastemas of Ambystoma. Dev. Dyn. 223: 193203.

Coletti, D., Moresi, V., Adamo, S., Molinaro, M., and Sassoon, D. 2005. Tumor necrosis factor- $\alpha$ gene transfer induces cachexia and inhibits muscle regeneration. Genesis 43: 120128.

Collins, R.A. and Grounds, M.D. 2001. The role of tumor necrosis factor- $\alpha(\mathrm{TNF}-\alpha)$ in skeletal muscle regeneration. Studies in TNF- $\alpha^{-/-}$and TNF- $\alpha^{-/-} / \mathrm{LT}-\alpha^{-/-}$mice. I. Histochem. Cytochem. 49: 989-1001.

Conboy, I.M. and Rando, T.A. 2002. The regulation of Notch signaling controls satellite cell activation and cell fate determination in postnatal myogenesis. Dev. Cell 3: 397-409.

Conboy, I.M., Conboy, M.J., Smythe, G.M., and Rando, T.A. 2003. Notch-mediated restoration of regenerative potential to aged muscle. Science 302: 1575-1577.

Conboy, I.M., Conboy, M.J., Wagers, A.J., Girma, E.R., Weissman, I.L., and Rando, T.A. 2005. Rejuvenation of aged progenitor cells by exposure to a young systemic environment. Nature 433: 760-764.

Corbel, S.Y., Lee, A., Yi, L., Duenas, J., Brazelton, T.R., Blau, H.M., and Rossi, F.M. 2003. Contribution of hematopoietic stem cells to skeletal muscle. Nat. Med. 9: 1528-1532.

Cornell, R.P., Liliequist, B.L., and Bartizal, K.F. 1990. Depressed liver regeneration after partial hepatectomy of germ-free, athymic and lipopolysaccharide-resistant mice. Hepatology 11: 916-922.

da Silva, S.M., Gates, P.B., and Brockes, J.P. 2002. The newt ortholog of CD59 is implicated in proximodistal identity during amphibian limb regeneration. Dev. Cell 3: 547-555.

Date, M., Matsuzaki, K., Matsushita, M., Tahashi, Y., Sakitani, K., and Inoue, K. 2000. Differential regulation of activin A for hepatocyte growth and fibronectin synthesis in rat liver injury. J. Hepatol. 32: 251-260.

Dent, J.N. 1962. Limb regeneration in larvae and metamorphos- 
ing individuals of the South African clawed toad. J. Morphol. 110: $61-77$.

D’Jamoos, C.A., McMahon, G., and Tsonis, P.A. 1998. Fibroblast growth factor receptors regulate the ability for hindlimb regeneration in Xenopus laevis. Wound Repair Regen. 6: 388-397.

Douglas, B.S. 1972. Conservative management of guillotine amputation of the finger in children. Aust. Paediatr. J. 8: 86-89.

Dufourcq, P. and Vriz, S. 2006. The chemokine SDF-1 regulates blastema formation during zebrafish fin regeneration. Dev. Genes Evol. 216: 635-639.

Dunis, D.A. and Namenwirth, M. 1977. The role of grafted skin in the regeneration of X-irradiated axolotl limbs. Dev. Biol. 56: $97-109$.

Echeverri, K., Clarke, J.D., and Tanaka, E.M. 2001. In vivo imaging indicates muscle fiber dedifferentiation is a major contributor to the regenerating tail blastema. Dev. Biol. 236: $151-164$.

Endo, T., Yokoyama, H., Tamura, K., and Ide, H. 1997. Shh expression in developing and regenerating limb buds of Xenopus laevis. Dev. Dyn. 209: 227-232.

Endo, T., Bryant, S.V., and Gardiner, D.M. 2004. A stepwise model system for limb regeneration. Dev. Biol. 270: 135145.

Engel, F.B., Hsieh, P.C., Lee, R.T., and Keating, M.T. 2006. FGF1/p38 MAP kinase inhibitor therapy induces cardiomyocyte mitosis, reduces scarring, and rescues function after myocardial infarction. Proc. Natl. Acad. Sci. 103: 1554615551.

Evarts, R.P., Nagy, P., Marsden, E., and Thorgeirsson, S.S. 1987. A precursor-product relationship exists between oval cells and hepatocytes in rat liver. Carcinogenesis 8: 1737-1740.

Evarts, R.P., Nagy, P., Nakatsukasa, H., Marsden, E., and Thorgeirsson, S.S. 1989. In vivo differentiation of rat liver oval cells into hepatocytes. Cancer Res. 49: 1541-1547.

Evarts, R.P., Hu, Z., Fujio, K., Marsden, E.R., and Thorgeirsson, S.S. 1993. Activation of hepatic stem cell compartment in the rat: Role of transforming growth factor $\alpha$, hepatocyte growth factor, and acidic fibroblast growth factor in early proliferation. Cell Growth Differ. 4: 555-561.

Fausto, N. 2004. Liver regeneration and repair: Hepatocytes, progenitor cells, and stem cells. Hepatology 39: 1477-1487.

Fausto, N., Campbell, J.S., and Riehle, K.J. 2006. Liver regeneration. Hepatology 43 (Suppl. 1): S45-S53.

Ferrari, G., Cusella-De Angelis, G., Coletta, M., Paolucci, E., Stornaiuolo, A., Cossu, G., and Mavilio, F. 1998. Muscle regeneration by bone marrow-derived myogenic progenitors. Science 279: 1528-1530.

Fiore, F., Sebille, A., and Birnbaum, D. 2000. Skeletal muscle regeneration is not impaired in $\mathrm{Fgf6}^{-/-}$mutant mice. Biochem. Biophys. Res. Commun. 272: 138-143.

Flink, I.L. 2002. Cell cycle reentry of ventricular and atrial cardiomyocytes and cells within the epicardium following amputation of the ventricular apex in the axolotl, Amblystoma mexicanum: Confocal microscopic immunofluorescent image analysis of bromodeoxyuridine-labeled nuclei. Anat. Embryol. (Berl.) 205: 235-244.

Floss, T., Arnold, H.H., and Braun, T. 1997. A role for FGF-6 in skeletal muscle regeneration. Genes \& Dev. 11: 2040-2051.

Fujita, J., Marino, M.W., Wada, H., Jungbluth, A.A., Mackrell, P.J., Rivadeneira, D.E., Stapleton, P.P., and Daly, J.M. 2001. Effect of TNF gene depletion on liver regeneration after partial hepatectomy in mice. Surgery 129: 48-54.

Gargioli, C. and Slack, J.M. 2004. Cell lineage tracing during Xenopus tail regeneration. Development 131: 2669-2679.

Geraudie, J. and Landis, W.J. 1982. The fine structure of the developing pelvic fin dermal skeleton in the trout Salmo gairdneri. Am. J. Anat. 163: 141-156.

Geraudie, J. and Singer, M. 1992. The fish fin regenerate. Monogr. Dev. Biol. 23: 62-72.

Girgenrath, M., Weng, S., Kostek, C.A., Browning, B., Wang, M., Brown, S.A., Winkles, J.A., Michaelson, J.S., Allaire, N., Schneider, P., et al. 2006. TWEAK, via its receptor Fn14, is a novel regulator of mesenchymal progenitor cells and skeletal muscle regeneration. EMBO J. 25: 5826-5839.

Godwin, J.W. and Brockes, J.P. 2006. Regeneration, tissue injury and the immune response. J. Anat. 209: 423-432.

Grobet, L., Martin, L.J., Poncelet, D., Pirottin, D., Brouwers, B., Riquet, J., Schoeberlein, A., Dunner, S., Menissier, F., Massabanda, J., et al. 1997. A deletion in the bovine myostatin gene causes the double-muscled phenotype in cattle. Nat. Genet. 17: 71-74.

Gussoni, E., Soneoka, Y., Strickland, C.D., Buzney, E.A., Khan, M.K., Flint, A.F., Kunkel, L.M., and Mulligan, R.C. 1999. Dystrophin expression in the $\mathrm{mdx}$ mouse restored by stem cell transplantation. Nature 401: 390-394.

Haas, H.J. 1962. Studies on mechanisms of joint and bone formation in the skeleton rays of fish fins. Dev. Biol. 5: 1-34.

Hall, B.K. and Miyake, T. 2000. All for one and one for all: Condensations and the initiation of skeletal development. Bioessays 22: 138-147.

Han, M.J., An, J.Y., and Kim, W.S. 2001. Expression patterns of Fgf- 8 during development and limb regeneration of the axolotl. Dev. Dyn. 220: 40-48.

Han, M., Yang, X., Farrington, J.E., and Muneoka, K. 2003. Digit regeneration is regulated by Msx1 and BMP4 in fetal mice. Development 130: 5123-5132.

Han, M., Yang, X., Taylor, G., Burdsal, C.A., Anderson, R.A., and Muneoka, K. 2005. Limb regeneration in higher vertebrates: Developing a roadmap. Anat. Rec. B New Anat. 287: 14-24.

Hay, E.D. and Fischman, D.A. 1961. Origin of the blastema in regenerating limbs of the newt Triturus viridescens. An autoradiographic study using tritiated thymidine to follow cell proliferation and migration. Dev. Biol. 3: 26-59.

Hayamizu, T.F., Wanek, N., Taylor, G., Trevino, C., Shi, C., Anderson, R., Gardiner, D.M., Muneoka, K., and Bryant, S.V. 1994. Regeneration of HoxD expression domains during pattern regulation in chick wing buds. Dev. Biol. 161: 504-512.

Hayashi, H., Nagaki, M., Imose, M., Osawa, Y., Kimura, K., Takai, S., Imao, M., Naiki, T., Kato, T., and Moriwaki, H. 2005. Normal liver regeneration and liver cell apoptosis after partial hepatectomy in tumor necrosis factor- $\alpha$-deficient mice. Liver Int. 25: 162-170.

Herrera, M.B., Bruno, S., Buttiglieri, S., Tetta, C., Gatti, S., Deregibus, M.C., Bussolati, B., and Camussi, G. 2006. Isolation and characterization of a stem cell population from adult human liver. Stem Cells 24: 2840-2850.

Huang, C.C., Lawson, N.D., Weinstein, B.M., and Johnson, S.L. 2003. reg6 is required for branching morphogenesis during blood vessel regeneration in zebrafish caudal fins. Dev. Biol. 264: 263-274.

Huh, C.G., Factor, V.M., Sanchez, A., Uchida, K., Conner, E.A., and Thorgeirsson, S.S. 2004. Hepatocyte growth factor/cmet signaling pathway is required for efficient liver regeneration and repair. Proc. Nat1. Acad. Sci. 101: 4477-4482.

Husmann, I., Soulet, L., Gautron, J., Martelly, I., and Barritault, D. 1996. Growth factors in skeletal muscle regeneration. Cytokine Growth Factor Rev. 7: 249-258.

Hwang, S.G., Ryu, J.H., Kim, I.C., Jho, E.H., Jung, H.C., Kim, K., Kim, S.J., and Chun, J.S. 2004. Wnt-7a causes loss of differentiated phenotype and inhibits apoptosis of articular chon- 
drocytes via different mechanisms. I. Biol. Chem. 279: 26597-26604.

Illingworth, C.M. 1974. Trapped fingers and amputated finger tips in children. J. Pediatr. Surg. 9: 853-858.

Imokawa, Y. and Brockes, J.P. 2003. Selective activation of thrombin is a critical determinant for vertebrate lens regeneration. Curr. Biol. 13: 877-881.

Imokawa, Y. and Yoshizato, K. 1997. Expression of Sonic hedgehog gene in regenerating newt limb blastemas recapitulates that in developing limb buds. Proc. Natl. Acad. Sci. 94: 9159-9164.

Imokawa, Y., Simon, A., and Brockes, J.P. 2004. A critical role for thrombin in vertebrate lens regeneration. Philos. Trans. R. Soc. Lond. B Biol. Sci. 359: 765-776.

Jakubowski, A., Ambrose, C., Parr, M., Lincecum, J.M., Wang, M.Z., Zheng, T.S., Browning, B., Michaelson, J.S., Baetscher, M., Wang, B., et al. 2005. TWEAK induces liver progenitor cell proliferation. J. Clin. Invest. 115: 2330-2340.

Jo, C., Kim, H., Jo, I., Choi, I., Jung, S.C., Kim, J., Kim, S.S., and Jo, S.A. 2005. Leukemia inhibitory factor blocks early differentiation of skeletal muscle cells by activating ERK. Biochim. Biophys. Acta 1743: 187-197.

Johnson, S.L. and Weston, J.A. 1995. Temperature-sensitive mutations that cause stage-specific defects in zebrafish fin regeneration. Genetics 141: 1583-1595.

Kawakami, Y., Rodriguez Esteban, C., Raya, M., Kawakami, H., Marti, M., Dubova, I., and Izpisua Belmonte, J.C. 2006. Wnt/ $\beta$-catenin signaling regulates vertebrate limb regeneration. Genes \& Dev. 20: 3232-3237.

Kimura, Y., Madhavan, M., Call, M.K., Santiago, W., Tsonis, P.A., Lambris, J.D., and Del Rio-Tsonis, K. 2003. Expression of complement 3 and complement 5 in newt limb and lens regeneration. J. Immunol. 170: 2331-2339.

Kirillova, I., Chaisson, M., and Fausto, N. 1999. Tumor necrosis factor induces DNA replication in hepatic cells through nuclear factor $\mathrm{\kappa B}$ activation. Cell Growth Differ. 10: 819828.

Koniaris, L.G., McKillop, I.H., Schwartz, S.I., and Zimmers, T.A. 2003. Liver regeneration. J. Am. Coll. Surg. 197: 634659.

Korthuis, R.J., Grisham, M.B., and Granger, D.N. 1988. Leukocyte depletion attenuates vascular injury in postischemic skeletal muscle. Am. J. Physiol. 254: H823-H827.

Kostakopoulou, K., Vogel, A., Brickell, P., and Tickle, C. 1996. 'Regeneration' of wing bud stumps of chick embryos and reactivation of Msx-1 and Shh expression in response to FGF-4 and ridge signals. Mech. Dev. 55: 119-131.

Krampera, M., Pizzolo, G., Aprili, G., and Franchini, M. 2006. Mesenchymal stem cells for bone, cartilage, tendon and skeletal muscle repair. Bone 39: 678-683.

Kumar, A., Velloso, C.P., Imokawa, Y., and Brockes, J.P. 2000. Plasticity of retrovirus-labelled myotubes in the newt limb regeneration blastema. Dev. Biol. 218: 125-136.

Kumar, A., Velloso, C.P., Imokawa, Y., and Brockes, J.P. 2004. The regenerative plasticity of isolated urodele myofibers and its dependence on MSX1. PLoS Biol. doi: 10.1371/journal .pbio.0020218.

Kyriakides, C., Austen Jr., W., Wang, Y., Favuzza, J., Kobzik, L., Moore Jr., F.D., and Hechtman, H.B. 1999. Skeletal muscle reperfusion injury is mediated by neutrophils and the complement membrane attack complex. Am. J. Physiol. 277: C1263-C1268.

LaBarge, M.A. and Blau, H.M. 2002. Biological progression from adult bone marrow to mononucleate muscle stem cell to multinucleate muscle fiber in response to injury. Cell 111: 589-601.
Laforest, L., Brown, C.W., Poleo, G., Geraudie, J., Tada, M., Ekker, M., and Akimenko, M.A. 1998. Involvement of the sonic hedgehog, patched 1 and bmp2 genes in patterning of the zebrafish dermal fin rays. Development 125: 4175-4184.

Lee, S.J. 2004. Regulation of muscle mass by myostatin. Annu. Rev. Cell Dev. Biol. 20: 61-86.

Lee, Y., Grill, S., Sanchez, A., Murphy-Ryan, M., and Poss, K.D. 2005. Fgf signaling instructs position-dependent growth rate during zebrafish fin regeneration. Development 132: 51735183.

Lepilina, A., Coon, A.N., Kikuchi, K., Holdway, J.E., Roberts, R.W., Burns, C.G., and Poss, K.D. 2006. A dynamic epicardial injury response supports progenitor cell activity during zebrafish heart regeneration. Cell 127: 607-619.

Lesurtel, M., Graf, R., Aleil, B., Walther, D.J., Tian, Y., Jochum, W., Gachet, C., Bader, M., and Clavien, P.A. 2006. Plateletderived serotonin mediates liver regeneration. Science 312: 104-107.

Li, W., Liang, X., Leu, J.I., Kovalovich, K., Ciliberto, G., and Taub, R. 2001. Global changes in interleukin-6-dependent gene expression patterns in mouse livers after partial hepatectomy. Hepatology 33: 1377-1386.

Lien, C.L., Schebesta, M., Makino, S., Weber, G.J., and Keating, M.T. 2006. Gene expression analysis of zebrafish heart regeneration. PLOS Biol. doi: 10.1371/journal.pbio.0040260.

Lo, D.C., Allen, F., and Brockes, J.P. 1993. Reversal of muscle differentiation during urodele limb regeneration. Proc. Nat1. Acad. Sci. 90: 7230-7234.

Ludolph, D.C., Cameron, J.A., and Stocum, D.L. 1990. The effect of retinoic acid on positional memory in the dorsoventral axis of regenerating axolotl limbs. Dev. Biol. 140: 41-52.

Macias-Silva, M., Li, W., Leu, J.I., Crissey, M.A., and Taub, R. 2002. Up-regulated transcriptional repressors SnoN and Ski bind Smad proteins to antagonize transforming growth factor- $\beta$ signals during liver regeneration. J. Biol. Chem. 277: 28483-28490.

Maden, M. 1982. Vitamin A and pattern formation in the regenerating limb. Nature 295: 672-675.

Mari-Beffa, M., Mateos, I., Palmqvist, P., and Becerra, J. 1996. Cell to cell interactions during teleosts fin regeneration. Int. J. Dev. Biol. 40 (Suppl. 1): S179-S180.

Martin, P. 1997. Wound healing-Aiming for perfect skin regeneration. Science 276: 75-81.

Massimino, M.L., Rapizzi, E., Cantini, M., Libera, L.D., Mazzoleni, F., Arslan, P., and Carraro, U. 1997. ED2 ${ }^{+}$macrophages increase selectively myoblast proliferation in muscle cultures. Biochem. Biophys. Res. Commun. 235: 754-759.

Mastellos, D., Papadimitriou, J.C., Franchini, S., Tsonis, P.A., and Lambris, J.D. 2001. A novel role of complement: Mice deficient in the fifth component of complement (C5) exhibit impaired liver regeneration. J. Immunol. 166: 2479-2486.

McCroskery, S., Thomas, M., Maxwell, L., Sharma, M., and Kambadur, R. 2003. Myostatin negatively regulates satellite cell activation and self-renewal. J. Cell Biol. 162: 1135-1147.

McCroskery, S., Thomas, M., Platt, L., Hennebry, A., Nishimura, T., McLeay, L., Sharma, M., and Kambadur, R. 2005. Improved muscle healing through enhanced regeneration and reduced fibrosis in myostatin-null mice. J. Cell Sci. 118: 3531-3541.

McGann, C.J., Odelberg, S.J., and Keating, M.T. 2001. Mammalian myotube dedifferentiation induced by newt regeneration extract. Proc. Natl. Acad. Sci. 98: 13699-13704.

McPherron, A.C., Lawler, A.M., and Lee, S.J. 1997. Regulation of skeletal muscle mass in mice by a new TGF- $\beta$ superfamily member. Nature 387: 83-90.

Mercader, N., Leonardo, E., Piedra, M.E., Martinez, A.C., Ros, 
M.A., and Torres, M. 2000. Opposing RA and FGF signals control proximodistal vertebrate limb development through regulation of Meis genes. Development 127: 3961-3970.

Mercader, N., Tanaka, E.M., and Torres, M. 2005. Proximodistal identity during vertebrate limb regeneration is regulated by Meis homeodomain proteins. Development 132: 4131-4142.

Merly, F., Lescaudron, L., Rouaud, T., Crossin, F., and Gardahaut, M.F. 1999. Macrophages enhance muscle satellite cell proliferation and delay their differentiation. Muscle Nerve 22: $724-732$

Michalopoulos, G.K., Barua, L., and Bowen, W.C. 2005. Transdifferentiation of rat hepatocytes into biliary cells after bile duct ligation and toxic biliary injury. Hepatology 41: 535544.

Mimeault, M. and Batra, S.K. 2006. Concise review: Recent advances on the significance of stem cells in tissue regeneration and cancer therapies. Stem Cells 24: 2319-2345.

Mitchell, C., Nivison, M., Jackson, L.F., Fox, R., Lee, D.C., Campbell, J.S., and Fausto, N. 2005. Heparin-binding epidermal growth factor-like growth factor links hepatocyte priming with cell cycle progression during liver regeneration. $J$. Biol. Chem. 280: 2562-2568.

Mohammed, F.F., Smookler, D.S., Taylor, S.E., Fingleton, B., Kassiri, Z., Sanchez, O.H., English, J.L., Matrisian, L.M., Au, B., Yeh, W.C., et al. 2004. Abnormal TNF activity in Timp3 $3^{-/-}$mice leads to chronic hepatic inflammation and failure of liver regeneration. Nat. Genet. 36: 969-977.

Monga, S.P., Pediaditakis, P., Mule, K., Stolz, D.B., and Michalopoulos, G.K. 2001. Changes in WNT/ $\beta$-catenin pathway during regulated growth in rat liver regeneration. Hepatology 33: 1098-1109.

Morrison, J.I., Loof, S., He, P., and Simon, A. 2006. Salamander limb regeneration involves the activation of a multipotent skeletal muscle satellite cell population. J. Cell Biol. 172: 433-440.

Mourkioti, F. and Rosenthal, N. 2005. IGF-1, inflammation and stem cells: Interactions during muscle regeneration. Trends Immunol. 26: 535-542.

Mullen, L.M., Bryant, S.V., Torok, M.A., Blumberg, B., and Gardiner, D.M. 1996. Nerve dependency of regeneration: The role of Distal-less and FGF signaling in amphibian limb regeneration. Development 122: 3487-3497.

Muneoka, K., Fox, W.F., and Bryant, S.V. 1986a. Cellular contribution from dermis and cartilage to the regenerating limb blastema in axolotls. Dev. Biol. 116: 256-260.

Muneoka, K., Holler-Dinsmore, G., and Bryant, S.V. 1986b. Intrinsic control of regenerative loss in Xenopus laevis limbs. J. Exp. Zool. 240: 47-54.

Musaro, A., McCullagh, K., Paul, A., Houghton, L., Dobrowolny, G., Molinaro, M., Barton, E.R., Sweeney, H.L., and Rosenthal, N. 2001. Localized Igf-1 transgene expression sustains hypertrophy and regeneration in senescent skeletal muscle. Nat. Genet. 27: 195-200.

Namenwirth, M. 1974. The inheritance of cell differentiation during limb regeneration in the axolotl. Dev. Biol. 41: 42-56.

Nechiporuk, A. and Keating, M.T. 2002. A proliferation gradient between proximal and msxb-expressing distal blastema directs zebrafish fin regeneration. Development 129: 26072617.

Neff, A.W., Dent, A.E., and Armstrong, J.B. 1996. Heart development and regeneration in urodeles. Int. J. Dev. Biol. 40: 719-725.

Newsome, P.N., Hussain, M.A., and Theise, N.D. 2004. Hepatic oval cells: Helping redefine a paradigm in stem cell biology. Curr. Top. Dev. Biol. 61: 1-28.

Nguyen, H.X. and Tidball, J.G. 2003. Null mutation of gp91phox reduces muscle membrane lysis during muscle inflammation in mice. J. Physiol. 553: 833-841.

Niazi, I.A. and Saxena, S. 1978. Abnormal hind limb regeneration in tadpoles of the toad, Bufo andersoni, exposed to excess vitamin A. Folia Biol. (Krakow) 26: 3-8.

Oberpriller, J.O. and Oberpriller, J.C. 1974. Response of the adult newt ventricle to injury. J. Exp. Zool. 187: 249-253.

Odelberg, S.J., Kollhoff, A., and Keating, M.T. 2000. Dedifferentiation of mammalian myotubes induced by msx1. Cell 103: 1099-1109.

Oh, S.H., Hatch, H.M., and Petersen, B.E. 2002. Hepatic oval 'stem' cell in liver regeneration. Semin. Cell Dev. Biol. 13: 405-409.

Partridge, T. 2004. Reenthronement of the muscle satellite cell. Cell 119: 447-448.

Petrof, B.J., Shrager, J.B., Stedman, H.H., Kelly, A.M., and Sweeney, H.L. 1993. Dystrophin protects the sarcolemma from stresses developed during muscle contraction. Proc. Natl. Acad. Sci. 90: 3710-3714.

Poleo, G., Brown, C.W., Laforest, L., and Akimenko, M.A. 2001 Cell proliferation and movement during early fin regeneration in zebrafish. Dev. Dyn. 221: 380-390.

Polesskaya, A., Seale, P., and Rudnicki, M.A. 2003. Wnt signaling induces the myogenic specification of resident $\mathrm{CD} 45^{+}$ adult stem cells during muscle regeneration. Cell 113: 841852.

Poltorak, A., He, X., Smirnova, I., Liu, M.Y., Van Huffel, C., Du, X., Birdwell, D., Alejos, E., Silva, M., Galanos, C., et al. 1998. Defective LPS signaling in $\mathrm{C} 3 \mathrm{H} / \mathrm{HeJ}$ and $\mathrm{C} 57 \mathrm{BL} / 10 \mathrm{ScCr}$ mice: Mutations in Tlr4 gene. Science 282: 2085-2088.

Poss, K.D. 2006. Getting to the heart of regeneration in zebrafish. Semin. Cell Dev. Biol. 18: 36-45.

Poss, K.D., Shen, J., Nechiporuk, A., McMahon, G., Thisse, B., Thisse, C., and Keating, M.T. 2000. Roles for Fgf signaling during zebrafish fin regeneration. Dev. Biol. 222: 347-358.

Poss, K.D., Wilson, L.G., and Keating, M.T. 2002. Heart regeneration in zebrafish. Science 298: 2188-2190.

Poss, K.D., Keating, M.T., and Nechiporuk, A. 2003. Tales of regeneration in zebrafish. Dev. Dyn. 226: 202-210.

Quint, E., Smith, A., Avaron, F., Laforest, L., Miles, J., Gaffield, W., and Akimenko, M.A. 2002. Bone patterning is altered in the regenerating zebrafish caudal fin after ectopic expression of sonic hedgehog and bmp2b or exposure to cyclopamine. Proc. Natl. Acad. Sci. 99: 8713-8718.

Rabinovsky, E.D., Gelir, E., Gelir, S., Lui, H., Kattash, M., DeMayo, F.J., Shenaq, S.M., and Schwartz, R.J. 2003. Targeted expression of IGF-1 transgene to skeletal muscle accelerates muscle and motor neuron regeneration. FASEB J. 17: 53-55.

Raya, A., Koth, C.M., Buscher, D., Kawakami, Y., Itoh, T., Raya, R.M., Sternik, G., Tsai, H.J., Rodriguez-Esteban, C., and Izpisua-Belmonte, J.C. 2003. Activation of Notch signaling pathway precedes heart regeneration in zebrafish. Proc. Natl. Acad. Sci. 100 (Suppl. 1): 11889-11895.

Riddiford, L.M. 1960. Autoradiographic studies of tritiated thymidine infused into the blastema of the early regenerate in the adult newt, Triturus. J. Exp. Zool. 144: 25-31.

Riddle, R.D., Johnson, R.L., Laufer, E., and Tabin, C. 1993. Sonic hedgehog mediates the polarizing activity of the ZPA. Cell 75: 1401-1416.

Roegiers, F. and Jan, Y.N. 2004. Asymmetric cell division. Curr. Opin. Cell Biol. 16: 195-205.

Roy, S. and Gardiner, D.M. 2002. Cyclopamine induces digit loss in regenerating axolotl limbs. J. Exp. Zool. 293: 186-190.

Roy, S. and Levesque, M. 2006. Limb regeneration in axolotl: Is it superhealing? Sci. World J. 6: 12-25.

Roy, S., Gardiner, D.M., and Bryant, S.V. 2000. Vaccinia as a 
tool for functional analysis in regenerating limbs: Ectopic expression of Shh. Dev. Biol. 218: 199-205.

Rubart, M. and Field, L.J. 2006a. Cardiac regeneration: Repopulating the heart. Annu. Rev. Physiol. 68: 29-49.

Rubart, M. and Field, L.J. 2006b. Cell-based approaches for cardiac repair. Ann. N. Y. Acad. Sci. 1080: 34-48.

Russell, W.E., Kaufmann, W.K., Sitaric, S., Luetteke, N.C., and Lee, D.C. 1996. Liver regeneration and hepatocarcinogenesis in transforming growth factor- $\alpha$-targeted mice. Mol. Carcinog. 15: 183-189.

Ryffel, G.U., Werdien, D., Turan, G., Gerhards, A., Goosses, S., and Senkel, S. 2003. Tagging muscle cell lineages in development and tail regeneration using Cre recombinase in transgenic Xenopus. Nucleic Acids Res. doi: 10.1093/nar/ gng044.

Sage, C., Huang, M., Karimi, K., Gutierrez, G., Vollrath, M.A., Zhang, D.S., Garcia-Anoveros, J., Hinds, P.W., Corwin, J.T., Corey, D.P., et al. 2005. Proliferation of functional hair cells in vivo in the absence of the retinoblastoma protein. Science 307: 1114-1118.

Santamaria, J.A., Mari-Beffa, M., and Becerra, J. 1992. Interactions of the lepidotrichial matrix components during tail fin regeneration in teleosts. Differentiation 49: 143-150.

Santamaria, J.A., Mari-Beffa, M., Santos-Ruiz, L., and Becerra, J. 1996. Incorporation of bromodeoxyuridine in regenerating fin tissue of the goldfish Carassius auratus. J. Exp. Zool. 275: 300-307.

Santoni-Rugiu, E., Jelnes, P., Thorgeirsson, S.S., and Bisgaard, H.C. 2005. Progenitor cells in liver regeneration: Molecular responses controlling their activation and expansion. APMIS 113: 876-902.

Santos-Ruiz, L., Santamaria, J.A., Ruiz-Sanchez, J., and Becerra, J. 2002. Cell proliferation during blastema formation in the regenerating teleost fin. Dev. Dyn. 223: 262-272.

Saunders Jr., J.W. 1998. The proximo-distal sequence of origin of the parts of the chick wing and the role of the ectoderm. 1948. J. Exp. Zool. 282: 628-668.

Saunders Jr., J.W., Gasseling, M.T., and Errick, J.E. 1976. Inductive activity and enduring cellular constitution of a supernumerary apical ectodermal ridge grafted to the limb bud of the chick embryo. Dev. Biol. 50: 16-25.

Schnapp, E., Kragl, M., Rubin, L., and Tanaka, E.M. 2005. Hedgehog signaling controls dorsoventral patterning, blastema cell proliferation and cartilage induction during axolotl tail regeneration. Development 132: 3243-3253.

Schneider, J.W., Gu, W., Zhu, L., Mahdavi, V., and Nadal-Ginard, B. 1994. Reversal of terminal differentiation mediated by p107 in $\mathrm{Rb}^{-1-}$ muscle cells. Science 264: 1467-1471.

Seki, E., Tsutsui, H., Iimuro, Y., Naka, T., Son, G., Akira, S., Kishimoto, T., Nakanishi, K., and Fujimoto, J. 2005. Contribution of Toll-like receptor/myeloid differentiation factor 88 signaling to murine liver regeneration. Hepatology 41: 443450.

Sell, S. 2001. Heterogeneity and plasticity of hepatocyte lineage cells. Hepatology 33: 738-750.

Serandour, A.L., Loyer, P., Garnier, D., Courselaud, B., Theret, N., Glaise, D., Guguen-Guillouzo, C., and Corlu, A. 2005. TNF $\alpha$-mediated extracellular matrix remodeling is required for multiple division cycles in rat hepatocytes. Hepatology 41: 478-486.

Sherwood, R.I., Christensen, J.L., Conboy, I.M., Conboy, M.J., Rando, T.A., Weissman, I.L., and Wagers, A.J. 2004. Isolation of adult mouse myogenic progenitors: Functional heterogeneity of cells within and engrafting skeletal muscle. Cell 119: $543-554$.

Slack, J.M.W. 2007. The evolution of regeneration. In Heart development and regeneration (eds. N. Rosenthal and R. Harvey). Academic Press.

Smith, W.C. and Harland, R.M. 1992. Expression cloning of noggin, a new dorsalizing factor localized to the Spemann organizer in Xenopus embryos. Cell 70: 829-840.

Smith, A., Avaron, F., Guay, D., Padhi, B.K., and Akimenko, M.A. 2006. Inhibition of BMP signaling during zebrafish fin regeneration disrupts fin growth and scleroblasts differentiation and function. Dev. Biol. 299: 438-454.

Sodhi, D., Micsenyi, A., Bowen, W.C., Monga, D.K., Talavera, J.C., and Monga, S.P. 2005. Morpholino oligonucleotide-triggered $\beta$-catenin knockdown compromises normal liver regeneration. J. Hepatol. 43: 132-141.

Steen, T.P. 1968. Stability of chondrocyte differentiation and contribution of muscle to cartilage during limb regeneration in the axolotl (Siredon mexicanum). J. Exp. Zool. 167: 49-78.

Stoick-Cooper, C.L., Weidinger, G., Riehle, K.J., Hubbert, C., Major, M.B., Fausto, N., and Moon, R.T. 2007. Distinct Wnt signaling pathways have opposing roles in appendage regeneration. Development 134: 479-489.

Strey, C.W., Markiewski, M., Mastellos, D., Tudoran, R., Spruce, L.A., Greenbaum, L.E., and Lambris, J.D. 2003. The proinflammatory mediators $\mathrm{C} 3 \mathrm{a}$ and $\mathrm{C} 5 \mathrm{a}$ are essential for liver regeneration. J. Exp. Med. 198: 913-923.

Sturm, J., Keese, M., Zhang, H., Bonninghoff, R., Magdeburg, R., Vajkoczy, P., Dono, R., Zeller, R., and Gretz, N. 2004a. Liver regeneration in FGF-2-deficient mice: VEGF acts as potential functional substitute for FGF-2. Liver Int. 24: 161-168.

Sturm, J.W., Zhang, H., Magdeburg, R., Hasenberg, T., Bonninghoff, R., Oulmi, J., Keese, M., and McCuskey, R. 2004b. Altered apoptotic response and different liver structure during liver regeneration in FGF-2-deficient mice. Cell Physiol. Biochem. 14: 249-260.

Summerbell, D. 1974. A quantitative analysis of the effect of excision of the AER from the chick limb-bud. J. Embryol. Exp. Morphol. 32: 651-660.

Suzuki, A., Thies, R.S., Yamaji, N., Song, J.J., Wozney, J.M., Murakami, K., and Ueno, N. 1994. A truncated bone morphogenetic protein receptor affects dorsal-ventral patterning in the early Xenopus embryo. Proc. Natl. Acad. Sci. 91: 10255-10259.

Suzuki, A., Ueno, N., and Hemmati-Brivanlou, A. 1997. Xenopus msxl mediates epidermal induction and neural inhibition by BMP4. Development 124: 3037-3044.

Suzuki, M., Satoh, A., Ide, H., and Tamura, K. 2005. Nervedependent and -independent events in blastema formation during Xenopus froglet limb regeneration. Dev. Biol. 286: 361-375.

Takabe, K., Wang, L., Leal, A.M., Macconell, L.A., Wiater, E., Tomiya, T., Ohno, A., Verma, I.M., and Vale, W. 2003. Adenovirus-mediated overexpression of follistatin enlarges intact liver of adult rats. Hepatology 38: 1107-1115.

Tan, X., Behari, J., Cieply, B., Michalopoulos, G.K., and Monga, S.P. 2006. Conditional deletion of $\beta$-catenin reveals its role in liver growth and regeneration. Gastroenterology 131: 1561-1572.

Tanaka, E.M., Gann, A.A., Gates, P.B., and Brockes, J.P. 1997. Newt myotubes reenter the cell cycle by phosphorylation of the retinoblastoma protein. J. Cell Biol. 136: 155-165.

Tanaka, E.M., Drechsel, D.N., and Brockes, J.P. 1999. Thrombin regulates S-phase re-entry by cultured newt myotubes. Curr. Biol. 9: 792-799.

Taub, R. 2004. Liver regeneration: From myth to mechanism. Nat. Rev. Mol. Cell Biol. 5: 836-847.

Taylor, G.P., Anderson, R., Reginelli, A.D., and Muneoka, K. 1994. FGF-2 induces regeneration of the chick limb bud. 
Dev. Biol. 163: 282-284.

Teixeira, C.F., Zamuner, S.R., Zuliani, J.P., Fernandes, C.M., Cruz-Hofling, M.A., Fernandes, I., Chaves, F., and Gutierrez, J.M. 2003. Neutrophils do not contribute to local tissue damage, but play a key role in skeletal muscle regeneration, in mice injected with Bothrops asper snake venom. Muscle Nerve 28: 449-459.

Thoms, S.D. and Stocum, D.L. 1984. Retinoic acid-induced pattern duplication in regenerating urodele limbs. Dev. Biol. 103: 319-328.

Thornton, C.S. 1957. The effect of apical cap removal on limb regeneration in Amblystoma larvae. J. Exp. Zool. 134: 357381.

Tidball, J.G. 2005. Inflammatory processes in muscle injury and repair. Am. J. Physiol. Regul. Integr. Comp. Physiol. 288: R345-R353.

Torok, M.A., Gardiner, D.M., Izpisua-Belmonte, J.C., and Bryant, S.V. 1999. Sonic hedgehog (shh) expression in developing and regenerating axolotl limbs. J. Exp. Zool. 284: 197206.

Trowbridge, J.J., Xenocostas, A., Moon, R.T., and Bhatia, M. 2006. Glycogen synthase kinase-3 is an in vivo regulator of hematopoietic stem cell repopulation. Nat. Med. 12: 89-98.

Tschumi, P.A. 1957. The growth of the hindlimb bud of Xenopus laevis and its dependence upon the epidermis. J. Anat. 91: 149-173.

Tseng, A.S., Adams, D.S., Qiu, D., Koustubhan, P., and Levin, M. 2007. Apoptosis is required during early stages of tail regeneration in Xenopus laevis. Dev. Biol. 301: 62-69.

Tsonis, P.A. 1996. Limb regeneration. Cambridge University Press, Cambridge, UK.

Vinarsky, V., Atkinson, D.L., Stevenson, T.J., Keating, M.T., and Odelberg, S.J. 2005. Normal newt limb regeneration requires matrix metalloproteinase function. Dev. Biol. 279: 86-98.

Wagers, A.J. and Conboy, I.M. 2005. Cellular and molecular signatures of muscle regeneration: Current concepts and controversies in adult myogenesis. Cell 122: 659-667.

Wallace, H. 1981. Vertebrate limb regeneration. Wiley, New York.

Warren, G.L., Hulderman, T., Jensen, N., McKinstry, M., Mishra, M., Luster, M.I., and Simeonova, P.P. 2002. Physiological role of tumor necrosis factor $\alpha$ in traumatic muscle injury. FASEB J. 16: 1630-1632.

White, J.A., Boffa, M.B., Jones, B., and Petkovich, M. 1994. A zebrafish retinoic acid receptor expressed in the regenerating caudal fin. Development 120: 1861-1872.

Whitehead, G.G., Makino, S., Lien, C.L., and Keating, M.T. 2005. fgf20 is essential for initiating zebrafish fin regeneration. Science 310: 1957-1960.

Yin, L., Lynch, D., Ilic, Z., and Sell, S. 2002. Proliferation and differentiation of ductular progenitor cells and littoral cells during the regeneration of the rat liver to CCl4/2-AAF injury. Histol. Histopathol. 17: 65-81.

Yokoyama, H., Yonei-Tamura, S., Endo, T., Izpisua Belmonte, J.C., Tamura, K., and Ide, H. 2000. Mesenchyme with fgf-10 expression is responsible for regenerative capacity in Xenopus limb buds. Dev. Biol. 219: 18-29.

Yokoyama, H., Ide, H., and Tamura, K. 2001. FGF-10 stimulates limb regeneration ability in Xenopus laevis. Dev. Biol. 233: 72-79.

Yokoyama, H., Ogino, H., Stoick-Cooper, C.L., Grainger, R.M., and Moon, R.T. 2007. Wnt/ $\beta$-catenin signaling has an essential role in the initiation of limb regeneration. Dev. Biol. doi: 10.1016/j.ydbio.2007.1003.1014.

Zimmers, T.A., Davies, M.V., Koniaris, L.G., Haynes, P., Es- quela, A.F., Tomkinson, K.N., McPherron, A.C., Wolfman, N.M., and Lee, S.J. 2002. Induction of cachexia in mice by systemically administered myostatin. Science 296: $1486-1488$. 


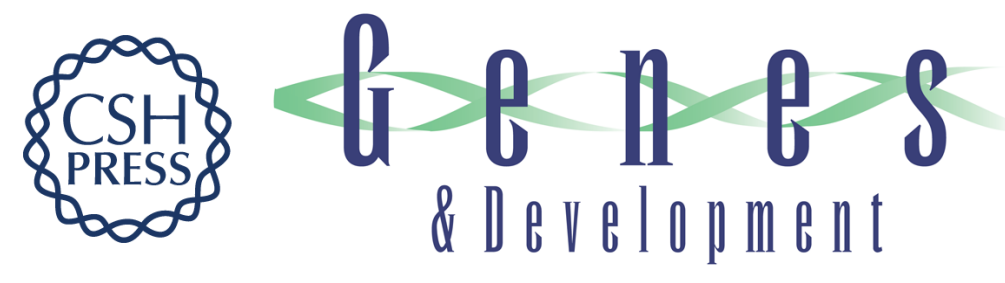

\section{Advances in signaling in vertebrate regeneration as a prelude to regenerative medicine}

Cristi L. Stoick-Cooper, Randall T. Moon and Gilbert Weidinger

Genes Dev. 2007, 21:

Access the most recent version at doi:10.1101/gad.1540507

References This article cites 210 articles, 55 of which can be accessed free at: http://genesdev.cshlp.org/content/21/11/1292.full.html\#ref-list-1

License

Email Alerting

Receive free email alerts when new articles cite this article - sign up in the box at the top Service right corner of the article or click here.

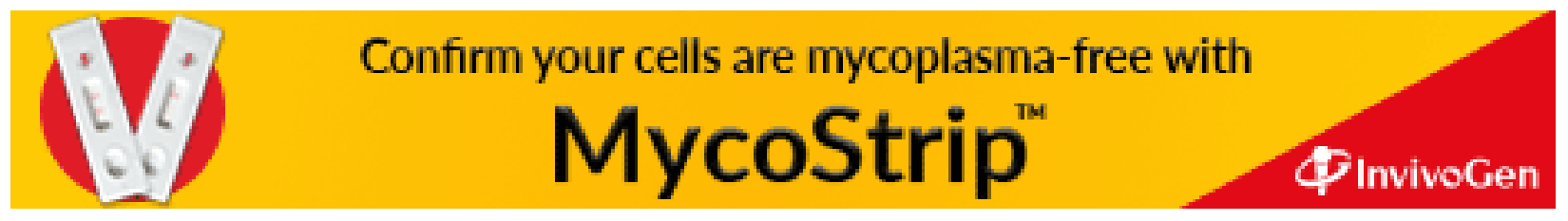

